\title{
Myocardial infarction differentially alters sphingolipid levels in plasma, erythrocytes and platelets of the rat
}

\author{
Małgorzata Knapp • Małgorzata Żendzian-Piotrowska • \\ Agnieszka Błachnio-Zabielska • Piotr Zabielski • \\ Krzysztof Kurek · Jan Górski
}

Received: 21 March 2012/Revised: 4 July 2012/ Accepted: 30 July 2012/Published online: 9 September 2012

(C) The Author(s) 2012. This article is published with open access at Springerlink.com

\begin{abstract}
Three bioactive sphingolipids, namely sphingosine-1-phosphate (S1P), ceramide (CER) and sphingosine (SPH) were shown to be involved in ischemia/ reperfusion injury of the heart. S1P is a powerful cardioprotectant, CER activates apoptosis and SPH in a low dose is cardioprotective whereas in a high dose is cardiotoxic. The aim of the present study was to examine effects of experimental myocardial infarction on the level of selected sphingolipids in plasma, erythrocytes and platelets in the rat. Myocardial infarction was produced in male Wistar rats by ligation of the left coronary artery. Blood was taken from the abdominal aorta at 1, 6 and $24 \mathrm{~h}$ after the ligation. Plasma, erythrocytes and platelets were isolated and S1P, dihydrosphingosine-1-phosphate (DHS1P), SPH, dihydrosphingosine (DHS) and CER were quantified by means of an Agilent 6460 triple quadrupole mass spectrometer using positive ion electrospray ionization source with multiple reaction monitoring. The infarction reduced the plasma level of S1P, DHS1P, SPH and DHS but increased the level of total CER. In erythrocytes, there was a sharp elevation in the level of SPH and DHS early after the infarction and a reduction after $24 \mathrm{~h}$ whereas the level of S1P, DHS1P and total CER gradually increased. In platelets, the level of each of the examined compounds profoundly decreased 1 and $6 \mathrm{~h}$ after the infarction and partially normalized in $24 \mathrm{~h}$. The results obtained clearly
\end{abstract}

\footnotetext{
M. Knapp ( $\square)$

Department of Cardiology, Medical University of Białystok, Skłodowskiej-Curie 24a, 15-276 Białystok, Poland e-mail: malgo33@interia.pl

M. Żendzian-Piotrowska · A. Błachnio-Zabielska . P. Zabielski · K. Kurek · J. Górski

Department of Physiology, Medical University of Białystok, Mickiewicza 2C, 15-089, Białystok, Poland
}

show that experimental heart infarction in rats produces deep changes in metabolism of sphingolipids in the plasma, platelets and erythrocytes.

Keywords Myocardial infarction - Sphingolipids · Plasma $\cdot$ Erythrocytes $\cdot$ Platelets $\cdot$ Rat

\section{Introduction}

It is well documented that certain bioactive sphingolipids, especially sphingosine-1-phosphate (S1P) and ceramide (CER) exert powerful effects on the heart response to experimental ischemia/reperfusion (I/R) injury. Interestingly, each of them exerts different effects. Extracellular S1P is a very powerful cardioprotectant. It was shown to increase viability of isolated cardiomyocytes subjected to hypoxia or ischemia/reperfusion [27, 48, 60]. Also, it was reported to reduce the infarct size and left ventricular end diastolic pressure (LVEDP) and to accelerate recovery of the left ventricular developed pressure (LVDP) in isolated, perfused rat and mouse hearts exposed to ischemia/reperfusion $[26,34,49,55] . \mathrm{S} 1 \mathrm{P}$ is claimed to be the principal mediator of ischemic pre- and post-conditioning [24, 25, 54]. It binds to the S1P receptors in the plasma membrane and the complex activates $G$ protein $[37,45]$. This, in turn, activates Akt kinase [16, 36, 38] and Stat3 [10, 15, 28] which have prosurvival properties. The kinases also play a key role in cardioprotective action of other mediators including $\mathrm{TNF} \alpha[20,30]$. Very recent contribution indicates on involvement of mitochondrial S1P in cardioprotection [18]. The main source of S1P in the plasma are erythrocytes [9, 19, 40, 45]. Platelets and endothelial cells also contribute to this pool of S1P $[29,51,57]$. I/R procedure was shown to increase the level of CER in the 
myocardium of rats and rabbits in vivo and in isolated, perfused rat heart $[3,5,12,13,59]$ and isolated cardiomyocytes [6]. CER is claimed to strongly activate apoptosis in the $I / R$ heart $[3,6]$. The data on effect of $I / R$ on behavior of sphingosine (SPH) in isolated, perfused heart are controversial: both elevation [11] and reduction [12] in its level was reported. SPH present in the perfusion medium in a high dose is cardiotoxic during I/R. On the other hand, at physiological concentration, it is cardioprotective [56]. SPH was shown to be involved in myocardial dysfunction resulted from microembolization of the coronary vessels in dogs [50]. It is also suggested that SPH contributes to a protective action of TNF $\alpha$ on cardiac mitochondria [33].

The data presented above indicate that the plasma S1P and SPH concentration may be an important factor affecting the heart function during ischemia and I/R. Todate, there are only two published studies available concerning the plasma concentration of selected sphingolipids after myocardial infarction and they concern humans. In one study, a $50 \%$ reduction in the total plasma concentration of S1P and dihydrosphingosine 1-phosphate (DHS1P) early after the infarction and in 5 days later was reported. The concentration of SPH, CER and dihydrosphingosine (DHS) remained stable [31]. In the other study [44], the total plasma S1P concentration after the infarction depended on the time after the event: it was stable at $<2 \mathrm{~h}$, elevated in 2-12 $\mathrm{h}$ and returned to the control, thereafter. Interestingly, the HDL-bound concentration of plasma S1P in patients early after myocardial infarction was found to be reduced whereas the concentration of non-HDL-bound S1P was elevated.

At present, there are no data on the effect of myocardial infarction on metabolism of sphingolipid intermediates in different blood compartments. The aim of the present study was to examine the level of S1P, SPH, DHS, DHS1P and CER in plasma, erythrocytes and platelets after ligation of the left coronary artery in rats.

\section{Methods}

The experimental procedure was approved by the Ethical Committee on the Animal Research at the Medical University of Białystok. Male Wistar rats, 200-220 g body weight (42-48 day old) were used. There were no age differences between the groups.

The procedure of ligation of the left coronary artery

The surgery was performed under thiopental anesthesia ( $80 \mathrm{mg} / 100 \mathrm{~g}$ of body weight). The thoracic cavity was opened in the left fifth intercostal space. The lungs were ventilated by frequent air puffs administered manually by means of a small rubber balloon connected with the rat's nose by means of a plastic tube. The heart was exteriorized, the pericardium was cut open and the left coronary artery was ligated with a 6-0 monofilament polypropylene suture thread (Surgipro). The heart was placed back in the thoracic cavity, the wound was sutured and the rat started to breath spontaneously. After the surgery the rats were placed in their home cages. The same procedure was applied during the sham surgery with the exception that the coronary artery was not ligated. The rate of survival of the rats subjected to the myocardial infarction was $60 \%$. In separate rats $(N=3)$, the ischemic area was determined $24 \mathrm{~h}$ after ligation of the left coronary artery using Evans Blue [35]. The area encompassed 35, 36 and $39 \%$ of the left ventricle.

\section{Ligation of the femoral artery}

The rats were anaesthetized as above. A small $(\sim 5 \mathrm{~mm})$ incision of the skin in the inguinal fossa was made, the femoral artery was separated bluntly from the vein and the artery was tied up. The incision was secured with two sutures. Since the incision was so small sham surgery was not performed. $6 \mathrm{~h}$ after ligation of the artery the rats were anaesthetized again and the blood was taken and processed as described below. The foot of the leg was pale and cold at the time of blood collection.

\section{Blood collection and fractionation}

Blood samples were drawn through a catheter inserted into an abdominal aorta. Sodium citrate was used as an anticoagulant. Immediately after sampling, $4 \mathrm{ml}$ of blood was centrifuged at $300 \times g$ for $10 \mathrm{~min}$ at room temperature and platelet-rich plasma was transferred to a fresh plastic tube. The leukocyte-rich buffy coat was thoroughly removed. Separated erythrocytes were suspended in $0.9 \% \mathrm{NaCl}$, centrifuged at $800 \times g$ for $10 \mathrm{~min}$ and the upper layer and the remaining buffy coat were discarded. Red blood cells were then resuspended in $2 \mathrm{ml}$ of $0.9 \% \mathrm{NaCl}$ and flash frozen in liquid nitrogen. Platelet-rich plasma was centrifuged at $1,000 \times g$ for $10 \mathrm{~min}$ to isolate platelets. Supernatant was then transferred to a fresh plastic tube and centrifuged at $5,000 \times g$ for $10 \mathrm{~min}$ to obtain platelet-free plasma. Isolated platelets were washed with platelet wash buffer $\left(5 \mathrm{mM} \mathrm{KH}_{2} \mathrm{PO}_{4}, 5 \mathrm{mM} \mathrm{Na}_{2} \mathrm{HPO}_{4}, 0.1 \mathrm{M} \mathrm{NaCl}, 1 \%\right.$ glucose, $0.63 \%$ sodium citrate, $\mathrm{pH}$ 6.6), suspended in $0.3 \mathrm{ml}$ of PBS, and flash frozen in liquid nitrogen. All samples were stored at $-80{ }^{\circ} \mathrm{C}$ until analysis.

The erythrocyte and platelet variables were measured in the blood using ABX Micros ABC Vet analyzer (Horiba). 
The plasma level of cardiac rat troponin I isoform (TNNI3) was measured with the use of commercially available ELISA assay (ELISA Kit for rat Troponin I Type 3) according to manufacturer's guidelines (USCN Life Science \& Technology Company, TX, USA).

The protein content in platelet samples and hemoglobin content in erythrocyte suspension was measured with the use of BCA-1 kit and Drabkin's reagent, respectively (both from Sigma-Aldrich, St. Louis, MO, USA).

\section{Determination of sphingolipids}

Standards utilizing 18C-sphingoid bases: sphingosine d18:1 (SPH) and dihydrosphingosine d18:0 (DHS), sphingosine-1phosphate d18:1 (S1P), dihydrosphingosine-1-phosphate (DHS1P), d18:1/14:0-Cer-ceramides containing myristic acid (C14:0-Cer), d18:1/16:0-Cer-ceramides containing palmitic acid (C16:0-Cer), d18:1/17:0-Cer-ceramides containing margaric acid (C17:0-Cer) - internal standard for ceramides, d18:1/18:0-Cer-ceramides containing stearic acid (C18:0-Cer), d18:1/18:1-Cer- ceramides containing oleic acid (C18:1-Cer), d18:1/20:0-Cer-ceramides containing arachidic acid (C20:0-Cer), d18:1/24:0-Cer-ceramides containing lignoceric acid (C24:0-Cer), d18:1/24:1$\mathrm{Cer}-$ ceramides containing nervonic acid (C24:1-Cer) as well as internal standards utilizing 17C-sphingoid bases: sphingosine (d17:1-SPH) — internal standard for sphingosine and dihydrosphingosine, sphingosine-1-phosphate (d17:1S1P)—internal standard for sphingosine-1-phosphate and dihydrosphingosine 1-phosphate, were purchased from Avanti Polar Lipids. Dihydrosphingosine-1-phosphate (d18:0) was purchased from Sigma-Aldrich (St. Louis, MO). HPLC grade methanol, water, formic acid, ammonium formate and ethanol were purchased from Sigma-Aldrich (St. Louis, MO). Sphingolipids were extracted from the plasma, erythrocytes and platelets by the use of the extraction mixture composed of isopropanol:water:ethyl acetate (35:5:60; v:v:v). The level of sphingolipids was determined according to [8]. The following sphingolipids were quantified: sphingosine, sphingosine1-phosphate, dihydrosphingosine (sphinganine), dihydrosphingosine-1-phosphate, ceramide C14:0, C16:0, C18:1, C18:0, C20:0, C22:0 C24:1 and C24:0. Sphingolipids were analyzed by means of an Agilent 6460 triple quadrupole mass spectrometer using positive ion electrospray ionization (ESI) source with multiple reaction monitoring (MRM). Chromatographic separation was performed using an Agilent 1290 Infinity Ultra Performance Liquid Chromatography (UPLC). The analytical column was a reverse-phase Zorbax SB-C8 column $2.1 \times 150 \mathrm{~mm}, 1.8 \mu \mathrm{m}$. Chromatographic separation was conducted in binary gradient using $2 \mathrm{mM}$ ammonium formate, $0.15 \%$ formic acid in methanol as Solvent A and $1.5 \mathrm{mM}$ ammonium formate, $0.1 \%$ formic acid in water as Solvent B at the flow rate of $0.4 \mathrm{ml} / \mathrm{min}$.

Determination of sphingosine kinase activity

Sphingosine kinase (SPHK) activity in blood platelets and erythrocytes was measured according to Vessey et al. [53] with minor modifications. Briefly, isolated platelets or erythrocytes were sonicated in $100 \mathrm{mM}$ Tris $\mathrm{HCl}$, $\mathrm{pH}=8.0$ for $30 \mathrm{~s}$ on ice. An aliquot of the sample corresponding to approx $100 \mu \mathrm{g}$ of platelet protein or erythrocyte hemoglobin was incubated for $15 \mathrm{~min}$. in assay buffer $(100 \mathrm{mM}$ Tris $\mathrm{HCl}, \mathrm{pH}=8.0,250 \mathrm{mM} \mathrm{KCl}$, $0.05 \%$ Triton $\mathrm{X}-100,20 \mathrm{mM} \mathrm{MgCl}_{2}$ ) with $10 \mathrm{mM}$ ATP and $5 \mu \mathrm{M}$ of $\left[3-{ }^{3} \mathrm{H}\right]$-sphingosine as substrates (approx. 400 DPM/pmol American Radiolabeled Chemicals Inc. St. Louis, MO, USA). Sodium fluoride, semicarbazide hydrochloride and $\beta$-glycerophosphate were added to a final concentration of $10 \mathrm{mM}, 2 \mathrm{mM}$ and $40 \mathrm{mM}$, respectively, to inhibit activity of lipid phosphatases and sphingosine-1phosphate lyase. The reaction was terminated by addition of ice-cold methanol followed by chloroform and $200 \mathrm{mM}$ EDTA. After vortexing/centrifugation aqueous phase containing water-soluble ${ }^{3} \mathrm{H}$-sphingosine-1-phosphate was collected. Radioactivity was measured by Packard 1900TR liquid scintillation counter. Activity of the enzyme was expressed in pmol of $\mathrm{S} 1 \mathrm{P} / \mathrm{min} / \mathrm{mg}$ of platelet protein or erythrocyte hemoglobin.

\section{Statistical analysis}

All data are presented as mean $\pm \mathrm{SD}$. Data were analyzed by ANOVA with Tukey HSD (Honestly Significant Difference) post hoc test for unequal sample size. $p<0.05$ is regarded as significant. Eight rats were used for each time point in either group with the exception of the sham operated group after $1 \mathrm{~h}(N=7)$.

\section{Results}

The erythrocyte and platelet variables (Table 1)

Neither ligation of the left coronary artery nor sham surgery affected the erythrocyte and platelets variables.

\section{Troponin T (Fig. 1)}

Troponin $\mathrm{T}$ was undetectable in the control and sham operated rats. It increased gradually after ligation of the left coronary artery so that after $6 \mathrm{~h}$ it was significantly higher 
Table 1 Erythrocyte and platelet variables in $6 \mathrm{~h}$ after ligation of the left coronary artery in the rat

\begin{tabular}{llcc}
\hline $\begin{array}{l}\text { Variable } \\
\text { (unit) }\end{array}$ & Control & Sham operated & $\begin{array}{c}\text { Ligation of the } \\
\text { coronary artery }\end{array}$ \\
\hline $\begin{array}{c}\text { RBC } \\
\left(10^{6} / \mu \mathrm{L}\right)\end{array}$ & $6.69 \pm 0.60$ & $6.66 \pm 0.50$ & $6.72 \pm 0.64$ \\
$\mathrm{HGB}(\mathrm{g} / \mathrm{dL})$ & $12.37 \pm 0.51$ & $12.96 \pm 0.26$ & $12.68 \pm 0.59$ \\
$\mathrm{HCT}(\%)$ & $34.70 \pm 2.38$ & $36.80 \pm 1.78$ & $35.84 \pm 5.70$ \\
$\mathrm{MCV}(\mathrm{fL})$ & $54.30 \pm 1.21$ & $54.12 \pm 5.05$ & $52.88 \pm 2.62$ \\
$\mathrm{MCH}(\mathrm{pg})$ & $19.39 \pm 0.43$ & $19.75 \pm 0.91$ & $19.50 \pm 0.41$ \\
$\mathrm{MCHC}$ & $35.74 \pm 1.40$ & $36.80 \pm 1.51$ & $36.80 \pm 1.50$ \\
$(\mathrm{~g} / \mathrm{dL})$ & & & \\
$\mathrm{PLT}$ & $920.29 \pm 106.81$ & $972.39 \pm 31.58$ & $962.71 \pm 36.08$ \\
$\left(10^{3} / \mu \mathrm{L}\right)$ & & & \\
$\mathrm{MPV}(\mathrm{fL})$ & $6.21 \pm 0.82$ & $6.49 \pm 0.44$ & $6.25 \pm 0.45$ \\
\hline
\end{tabular}

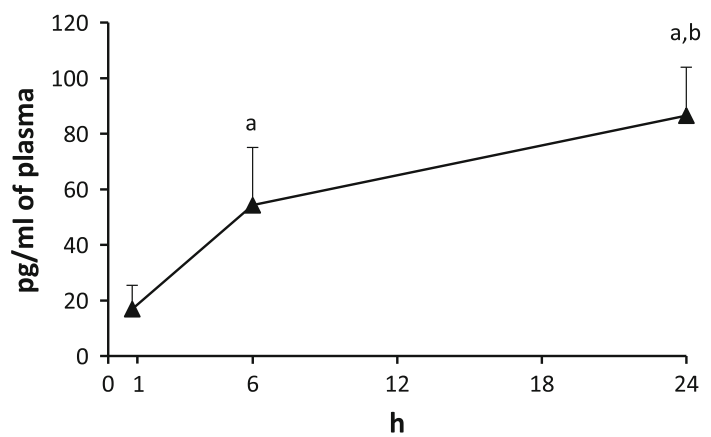

Fig. 1 The impact of myocardial infarction on the plasma concentration of rat cardiac troponin I (TNNI3, myocardial damage marker). Values from control and sham-operated groups were below the level of detection, and are not shown. Black vertical bars represent SD ( $n=6$ per group, with the exception of $24 \mathrm{~h}$ post-infract, $n=5$ ). $a p<0.001$ as compared with $1 \mathrm{~h}$ post-infarct group value, $b p<0.05$ as compared with $6 \mathrm{~h}$ post-infarct group value

Table 2 The control values of particular sphingolipids in the blood compartments

\begin{tabular}{lcrr}
\hline Compound & \multicolumn{1}{c}{ Plasma $^{\mathrm{a}}$} & Erythrocytes $^{\mathrm{b}}$ & \multicolumn{1}{c}{ Platelets $^{\mathrm{c}}$} \\
\hline SPH & $14.10 \pm 1.08$ & $3.65 \pm 0.36$ & $0.64 \pm 0.06$ \\
DHS & $9.08 \pm 0.71$ & $2.22 \pm 0.31$ & $0.35 \pm 0.03$ \\
S1P & $198.76 \pm 10.87$ & $5.45 \pm 0.41$ & $5.65 \pm 0.33$ \\
DHS1P & $49.29 \pm 1.97$ & $5.29 \pm 0.45$ & $2.64 \pm 0.19$ \\
CER & $2.03 \pm 0.1^{\mathrm{d}}$ & $21.03 \pm 1.43$ & $216.63 \pm 22.4$ \\
\hline
\end{tabular}

SPH sphingosine, DHS dihydrosphingosine, S1P sphingosine-1phosphate, DHS1P dihydrosphingosine-1-phosphate, CER ceramide

The numbers are mean $\pm \mathrm{SD}, N=8$

a $\mathrm{pmol} / \mathrm{ml}$

${ }^{b} \mathrm{pmol} / \mathrm{mg}$ of $\mathrm{Hb}$

c $\mathrm{pmol} / \mathrm{mg}$ of protein

${ }^{\mathrm{d}} \mathrm{nmol} / \mathrm{ml}$
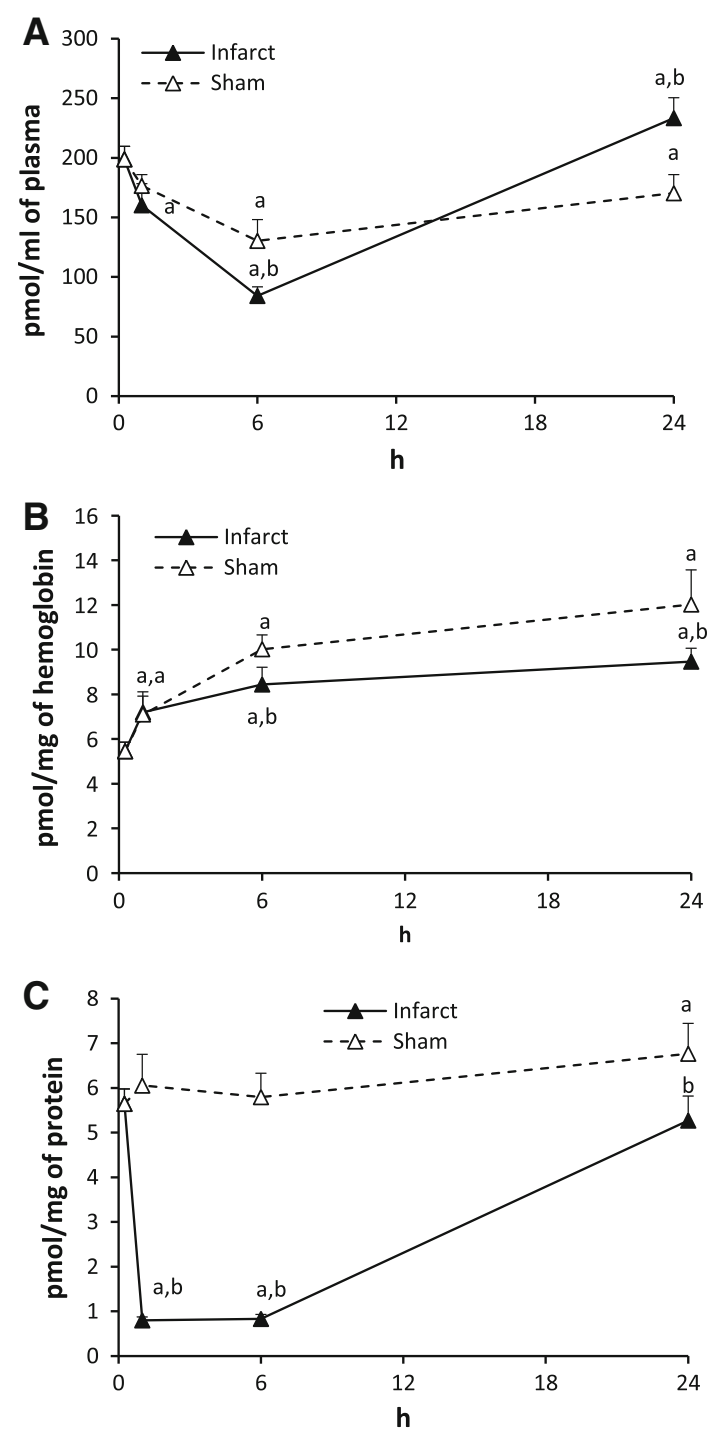

Fig. 2 The impact of myocardial infarction (black triangles) or sham operation (open triangles) on the level of sphingosine-1-phosphate (S1P) in blood plasma (A), erythrocytes (B) and platelets (C). Black vertical bars represent $\mathrm{SD}$. When bars not visible, SD is smaller than the size of the marker. $a p<0.05$ as compared to the control, $b p<0.05$ as compared to appropriate sham group

$(p<0.001)$ than after $1 \mathrm{~h}$ and after $24 \mathrm{~h}$ it was higher $(p<0.05)$ than after $6 \mathrm{~h}$.

\section{Sphingolipids}

The control levels of sphingolipids are presented in Table 2 .

Effect of ligation of the left coronary artery

Sphingosine-1-phosphate (SIP) (Fig. 2)

The level of S1P in the plasma after ligation of the artery (Infarct) decreased by $19.4 \%$ in $1 \mathrm{~h}$, by $57.7 \%$ in $6 \mathrm{~h}$ and 

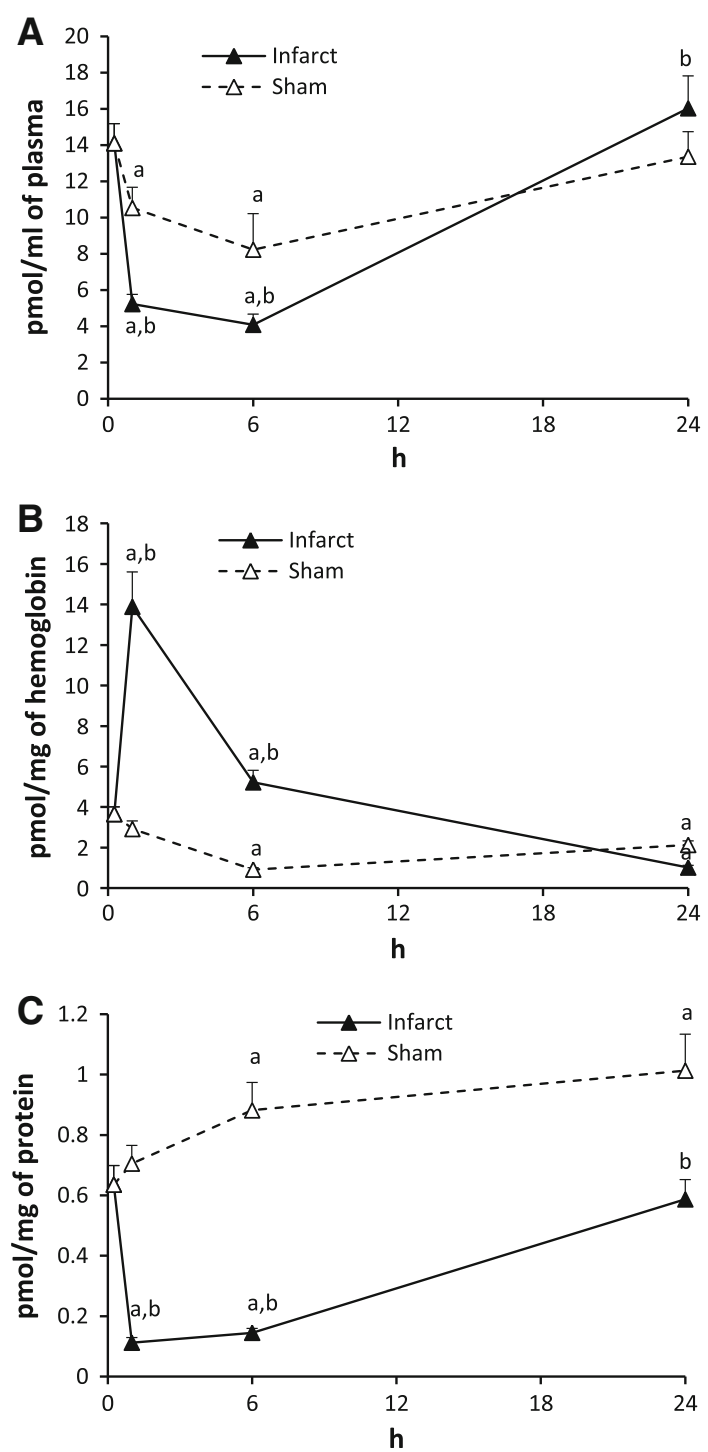

Fig. 3 The impact of myocardial infarction (black triangles) or sham operation (open triangles) on the level of sphingosine (SPH) in blood plasma (A), erythrocytes (B) and platelets (C). Black vertical bars represent SD. When bars not visible, SD is smaller than the size of the marker. $a p<0.05$ as compared to the control, $b p<0.05$ as compared to appropriate sham group

returned to the control value in $24 \mathrm{~h}$. In sham operated rats (Sham) the level of S1P decreased in $6 \mathrm{~h}$ but it was higher from the respective value in Infarct. It did not return to the control value in $24 \mathrm{~h}$.

The S1P level in erythrocytes was significantly higher at each time point both in Infarct and Sham as compared to the control value.

In platelets, the level of S1P in Infarct dropped down dramatically in 1 and $6 \mathrm{~h}$ (by 85.5 and $85.2 \%$, respectively) and returned to the control value in $24 \mathrm{~h}$. In Sham, the level of S1P in 1 and $6 \mathrm{~h}$ did not differ whereas in $24 \mathrm{~h}$ was higher from the control value.
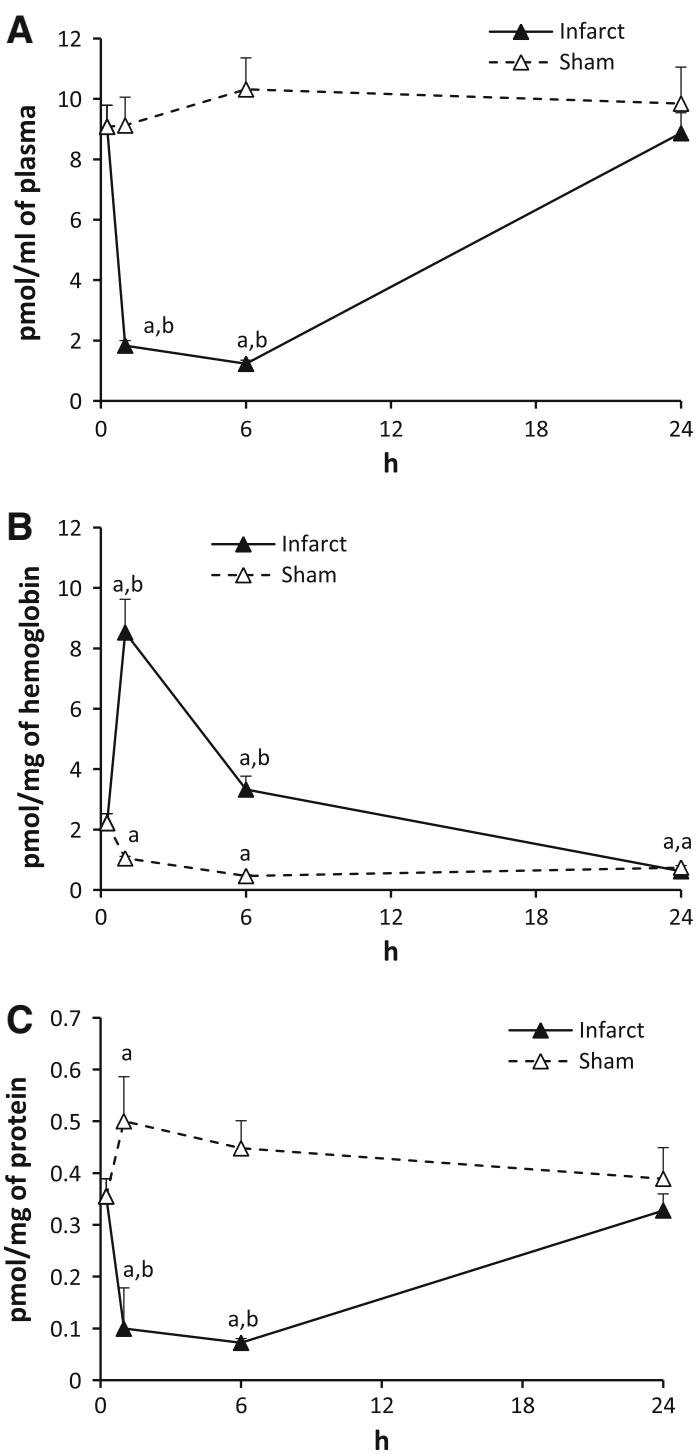

Fig. 4 The impact of myocardial infarction (black triangles) or sham operation (open triangles) on the level of dihydrosphingosine (DHS) in blood plasma (A), erythrocytes (B) and platelets (C). Black vertical bars represent $\mathrm{SD}$. When bars not visible, SD is smaller than the size of the marker. $a p<0.05$ as compared to the control, $b p<0.05$ as compared to appropriate sham group

\section{Sphingosine (SPH, Fig. 3)}

The plasma level of SPH in Infarct in 1 and $6 \mathrm{~h}$ was 2.8 and 3.5 times lower from the control, respectively. It returned to normal in $24 \mathrm{~h}$. In Sham, the level of SPH in 1 and $6 \mathrm{~h}$ was lower than the control but higher from the respective value in Infarct.

The level of SPH in erythrocytes of Infarct in $1 \mathrm{~h}$ increased 4 times over the control. In $6 \mathrm{~h}$ it was 1.5 times higher whereas in $24 \mathrm{~h}$ it dropped down and was 3.5 times lower than the control. In Sham, the content of SPH in $6 \mathrm{~h}$ and $24 \mathrm{~h}$ was lower than in the control. 

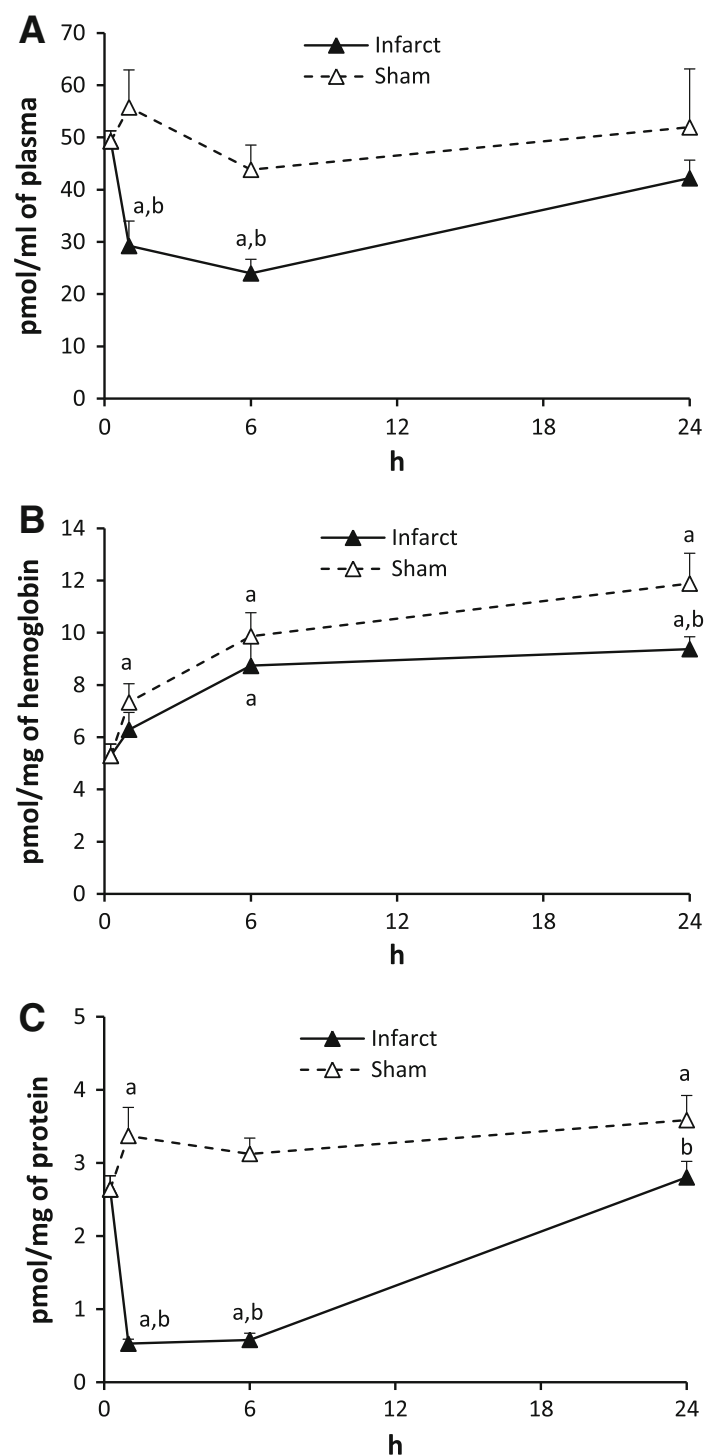

Fig. 5 The impact of myocardial infarction (black triangles) or sham operation (open triangles) on the level of dihydrosphingosine-1phosphate (DHS1P) in blood plasma (A), erythrocytes (B) and platelets (C). Black vertical bars represent SD. When bars not visible, $\mathrm{SD}$ is smaller than the size of the marker. $a p<0.05$ as compared to the control; $b p<0.05$ as compared to appropriate sham group

The level of SPH in the platelets of the Infarct in $1 \mathrm{~h}$ was nearly 6 times and in $6 \mathrm{~h}$ over 4 times lower than the control and in $24 \mathrm{~h}$ it returned to the control. In Sham, the level of SPH in 6 and $24 \mathrm{~h}$ was significantly higher than the control.

\section{Dihydrosphingosine (DHS, Fig. 4)}

The level of DHS in the plasma of Infarct in $1 \mathrm{~h}$ was over 5 times lower and in $6 \mathrm{~h}$ was over 7 times lower than the control. It returned to the control in $24 \mathrm{~h}$. Sham surgery did not affect the level of DHS.
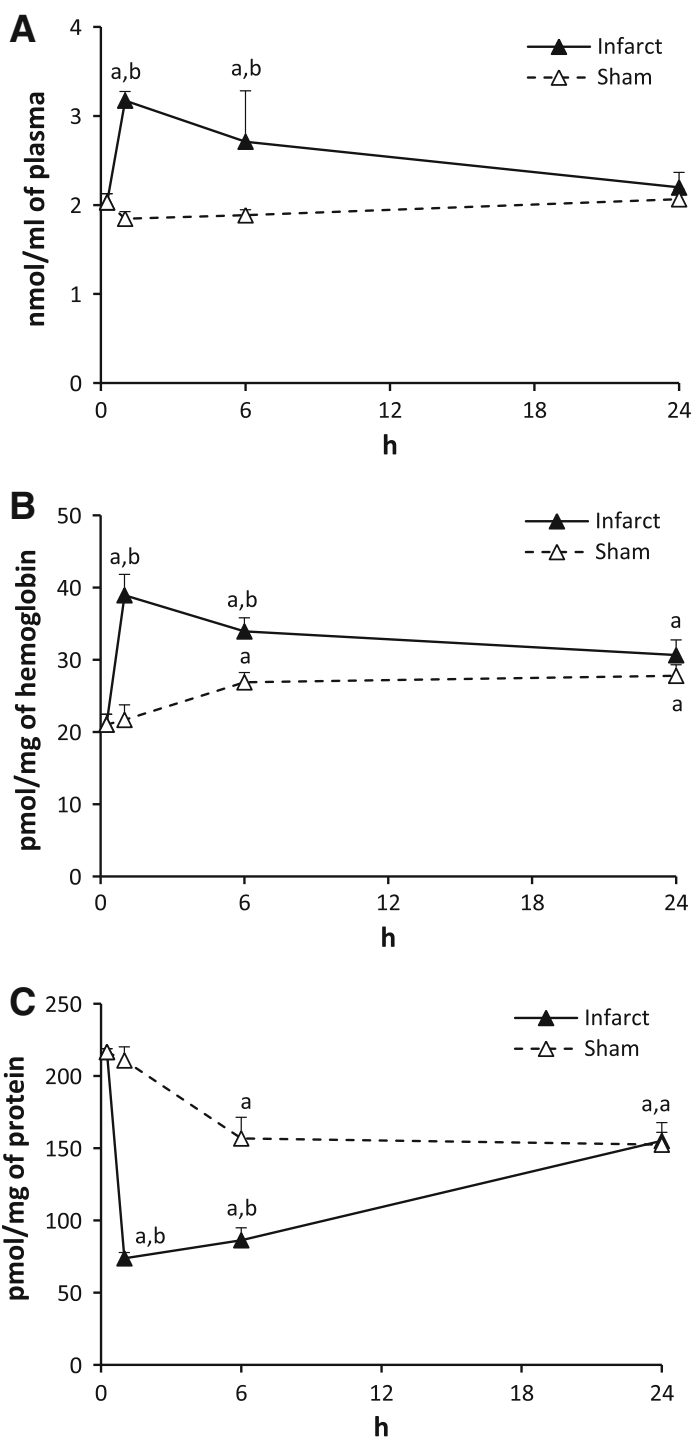

Fig. 6 The impact of myocardial infarction (black triangles) or sham operation (open triangles) on the total level of ceramide (CER) in blood plasma (A), erythrocytes (B) and platelets (C). Black vertical bars represent SD. When bars not visible, SD is smaller than the size of the marker. $a p<0.05$ as compared to the control, $b p<0.05$ as compared to appropriate sham group

In erythrocytes, the level of DHS in Infarct in $1 \mathrm{~h}$ increased 3.8 times over the control. Then, in $6 \mathrm{~h}$ it decreased to a value 1,5 times higher than the control whereas in $24 \mathrm{~h}$ it was 3.6 times lower than the control. In Sham, the level of DHS was markedly lower than the control at each time point.

In platelets, the level of DHS in Infarct in 1 and $6 \mathrm{~h}$ was over 3 times lower than the control and returned to the normal after $24 \mathrm{~h}$. In Sham, the level of DHS increased significantly in $1 \mathrm{~h}$ and then returned to normal. 
Table 3 Effect of myocardial infarction on the level of individual ceramides in plasma of the rat presented at the Table 2 and the Fig. 5

$\mathrm{pmol} / \mathrm{ml}$, values are mean $\pm \mathrm{SD}$

$I$ infarct, $S$ sham operated,

$N=8$ with the exception of

sham 1 h where $N=7$

${ }^{\mathrm{a}} p<0.05$ as compared to the control

${ }^{\mathrm{b}} p<0.05$ as compared to the respective value in the Sham group

Table 4 Effect of myocardial infarction on the level of individual ceramides in erythrocytes $(\mathrm{pmol} / \mathrm{mg} \mathrm{Hb})$ of the rat

\begin{tabular}{|c|c|c|c|c|c|c|c|}
\hline \multirow{2}{*}{$\frac{\text { Ceramide }}{\text { C14 }}$} & \multirow{2}{*}{$\begin{array}{l}\text { Control } \\
220.71 \pm 17.75\end{array}$} & \multicolumn{2}{|c|}{$1 \mathrm{~h}$} & \multicolumn{2}{|c|}{$6 \mathrm{~h}$} & \multicolumn{2}{|c|}{$24 \mathrm{~h}$} \\
\hline & & I & $219.75 \pm 26.79$ & I & $4.10 \pm 0.65^{\mathrm{a}, \mathrm{b}}$ & I & $192.27 \pm 17.38$ \\
\hline & & $\mathrm{S}$ & $181.98 \pm 28.01$ & $\mathrm{~S}$ & $209.32 \pm 40.82$ & $\mathrm{~S}$ & $232.87 \pm 40.95$ \\
\hline \multirow[t]{2}{*}{$\mathrm{C} 16$} & \multirow[t]{2}{*}{$278.60 \pm 20.39$} & I & $555.60 \pm 23.96^{\mathrm{a}, \mathrm{b}}$ & I & $350.27 \pm 34.95^{\mathrm{a}, \mathrm{b}}$ & I & $387.60 \pm 41.83^{\mathrm{a}, \mathrm{b}}$ \\
\hline & & $\mathrm{S}$ & $327.12 \pm 41.03$ & $\mathrm{~S}$ & $428.48 \pm 44.75^{\mathrm{a}}$ & $\mathrm{S}$ & $303.53 \pm 40.92$ \\
\hline \multirow[t]{2}{*}{$\mathrm{C} 18$} & \multirow[t]{2}{*}{$3.55 \pm 0.30$} & I & $3.73 \pm 0.34^{\mathrm{b}}$ & I & $3.83 \pm 0.55$ & I & $6.29 \pm 1.59^{\mathrm{a}, \mathrm{b}}$ \\
\hline & & $\mathrm{S}$ & $5.21 \pm 0.60^{\mathrm{a}}$ & $\mathrm{S}$ & $5.12 \pm 0.67^{\mathrm{a}}$ & $\mathrm{S}$ & $4.19 \pm 0.39$ \\
\hline \multirow[t]{2}{*}{$\mathrm{C} 18: 1$} & \multirow[t]{2}{*}{$4.15 \pm 0.30$} & I & $4.36 \pm 0.57$ & I & $4.77 \pm 0.41$ & I & $5.57 \pm 0.62^{\mathrm{a}}$ \\
\hline & & $\mathrm{S}$ & $4.08 \pm 0.94$ & $\mathrm{~S}$ & $4.08 \pm 0.39$ & $\mathrm{~S}$ & $4.56 \pm 0.83$ \\
\hline \multirow[t]{2}{*}{$\mathrm{C} 20$} & \multirow[t]{2}{*}{$4.80 \pm 0.45$} & I & $7.10 \pm 0.42^{\mathrm{a}, \mathrm{b}}$ & I & $5.79 \pm 0.76$ & I & $6.21 \pm 0.52^{\mathrm{a}}$ \\
\hline & & $S$ & $4.60 \pm 0.40$ & $\mathrm{~S}$ & $5.81 \pm 1.08$ & $\mathrm{~S}$ & $5.34 \pm 0.69$ \\
\hline \multirow[t]{2}{*}{$\mathrm{C} 22$} & \multirow[t]{2}{*}{$92.68 \pm 8.21$} & I & $135.12 \pm 14.87^{\mathrm{a}, \mathrm{b}}$ & I & $166.06 \pm 19.63^{\mathrm{a}, \mathrm{b}}$ & I & $122.69 \pm 11.93^{\mathrm{a}, \mathrm{b}}$ \\
\hline & & $\mathrm{S}$ & $80.44 \pm 7.93$ & $\mathrm{~S}$ & $65.52 \pm 15.51^{\mathrm{a}}$ & $\mathrm{S}$ & $67.81 \pm 12.41$ \\
\hline \multirow[t]{2}{*}{$\mathrm{C} 24$} & \multirow[t]{2}{*}{$1207.13 \pm 83.08$} & I & $1928.42 \pm 94.92^{\mathrm{a}, \mathrm{b}}$ & I & $1894.13 \pm 523.12^{\mathrm{a}, \mathrm{b}}$ & I & $1163.07 \pm 105.89$ \\
\hline & & $\mathrm{S}$ & $1089.15 \pm 108.61$ & $\mathrm{~S}$ & $1016.76 \pm 84.22$ & $\mathrm{~S}$ & $1249.32 \pm 80.48$ \\
\hline \multirow[t]{2}{*}{ C24:1 } & \multirow[t]{2}{*}{$217.76 \pm 8.36$} & I & $318.56 \pm 34.98^{\mathrm{a}, \mathrm{b}}$ & I & $282.53 \pm 12.16^{\mathrm{a}, \mathrm{b}}$ & I & $312.85 \pm 38.31^{\mathrm{a}, \mathrm{b}}$ \\
\hline & & $\mathrm{S}$ & $153.77 \pm 19.40^{\mathrm{a}}$ & $\mathrm{S}$ & $149.51 \pm 15.07^{\mathrm{a}}$ & $\mathrm{S}$ & $196.48 \pm 20.92$ \\
\hline
\end{tabular}

\begin{tabular}{|c|c|c|c|c|c|c|c|}
\hline \multirow{2}{*}{$\begin{array}{l}\text { Ceramide } \\
\mathrm{C} 14\end{array}$} & \multirow{2}{*}{$\begin{array}{l}\text { Control } \\
0.068 \pm 0.006\end{array}$} & \multicolumn{2}{|c|}{$1 \mathrm{~h}$} & \multicolumn{2}{|c|}{$6 \mathrm{~h}$} & \multicolumn{2}{|c|}{$24 \mathrm{~h}$} \\
\hline & & I & $0.123 \pm 0.011^{\mathrm{a}, \mathrm{b}}$ & I & $0.080 \pm 0.010^{\mathrm{b}}$ & I & $0.078 \pm 0.006$ \\
\hline & & $S$ & $0.058 \pm 0.007$ & S & $0.056 \pm 0.005$ & $\mathrm{~S}$ & $0.075 \pm 0.009$ \\
\hline \multirow[t]{2}{*}{$\mathrm{C} 16$} & $5.226 \pm 0.406$ & I & $8.979 \pm 0.877^{\mathrm{a}, \mathrm{b}}$ & I & $6.108 \pm 0.610$ & I & $5.838 \pm 0.644$ \\
\hline & & $\mathrm{S}$ & $5.139 \pm 0.606$ & S & $5.792 \pm 0.499$ & $\mathrm{~S}$ & $6.112 \pm 0.499$ \\
\hline \multirow[t]{2}{*}{$\mathrm{C} 18$} & $0.194 \pm$ & I & $0.594 \pm 0.063^{\mathrm{a}, \mathrm{b}}$ & I & $0.440 \pm 0.028^{\mathrm{a}, \mathrm{b}}$ & I & $0.256 \pm 0.027^{\mathrm{a}}$ \\
\hline & & $\mathrm{S}$ & $0.198 \pm 0.032$ & $\mathrm{~S}$ & $0.264 \pm 0.022 \mathrm{a}$ & $\mathrm{S}$ & $0.239 \pm 0.021$ \\
\hline \multirow[t]{2}{*}{ C18:1 } & $0.082 \pm$ & I & $0.160 \pm 0.016^{\mathrm{a}, \mathrm{b}}$ & I & $0.116 \pm 0.008^{\mathrm{a}, \mathrm{b}}$ & I & $0.089 \pm 0.007$ \\
\hline & & $\mathrm{S}$ & $0.087 \pm 0.007$ & $\mathrm{~S}$ & $0.086 \pm 0.007$ & $\mathrm{~S}$ & $0.086 \pm 0.009$ \\
\hline \multirow[t]{2}{*}{$\mathrm{C} 20$} & $0.103 \pm 0.009$ & I & $0.227 \pm 0.024^{\mathrm{a}, \mathrm{b}}$ & I & $0.207 \pm 0.025^{\mathrm{a}, \mathrm{b}}$ & I & $0.154 \pm 0.015^{\mathrm{a}, \mathrm{b}}$ \\
\hline & & & $0.129 \pm 0.016$ & $S$ & $0.137 \pm 0.014^{\mathrm{a}}$ & $S$ & $0.127 \pm 0.012$ \\
\hline \multirow[t]{2}{*}{$\mathrm{C} 22$} & $1.894 \pm 0.073$ & I & $3.561 \pm 0.454^{\mathrm{a}, \mathrm{b}}$ & I & $2.850 \pm 0.188^{b}$ & I & $2.468 \pm 0.242^{\mathrm{a}}$ \\
\hline & & $\mathrm{S}$ & $2.055 \pm 0.267$ & $\mathrm{~S}$ & $2.285 \pm 0.147$ & $\mathrm{~S}$ & $2.296 \pm 0.264$ \\
\hline \multirow[t]{2}{*}{$\mathrm{C} 24$} & $10.627 \pm 1.158$ & I & $18.982 \pm 1.831^{\mathrm{a}}$ & I & $19.232 \pm 1.459^{\mathrm{a}}$ & I & $17.309 \pm 1.154^{\mathrm{a}}$ \\
\hline & & $\mathrm{S}$ & $11.022 \pm 1.339$ & S & $14.814 \pm 0.886^{\mathrm{a}}$ & $\mathrm{S}$ & $15.451 \pm 1.415^{\mathrm{a}}$ \\
\hline \multirow[t]{2}{*}{$\mathrm{C} 24: 1$} & $2.835 \pm 0.193$ & I & $6.317 \pm 0.695^{\mathrm{a}, \mathrm{b}}$ & I & $4.901 \pm 0.306^{\mathrm{a}, \mathrm{b}}$ & I & $4.441 \pm 0.458^{\mathrm{a}}$ \\
\hline & & $\mathrm{S}$ & $2.996 \pm 0.333$ & $\mathrm{~S}$ & $3.445 \pm 0.327$ & S & $3.398 \pm 0.256$ \\
\hline
\end{tabular}

Total level of total ceramide is presented at the Table 2 and at the Fig. 5

Values are mean \pm SD

$I$ infarct, $S$ sham operated

$N=8$ with the exception of sham 1 h where $N=7$

${ }^{\text {a }} p<0.05$ as compared to the control

${ }^{\mathrm{b}} p<0.05$ as compared to the respective value in the Sham group

\section{Total ceramide (CER, Fig. 6)}

The level of DHS1P in plasma of Infarct decreased considerably in 1 and $6 \mathrm{~h}$ and returned to normal in $24 \mathrm{~h}$. In Sham, the concentration of the compound in the experimental groups did not differ from the control value.

The level of DHS1P in erythrocytes of Infarct in 6 and $24 \mathrm{~h}$ was significantly higher that the control. In Sham, the level of DHS1P was significantly higher than the control at each time point.

In platelets, the level of DHS1P in Infarct in 1 and $6 \mathrm{~h}$ was about 5 times lower than the control. In sham, it was elevated in 1 and $24 \mathrm{~h}$ compared to the control.
The plasma level of total CER in Infarct was elevated in 1 and $6 \mathrm{~h}$ whereas in Sham it remained stable at each time point.

The level of total CER in erythrocytes in Infarct was markedly higher than the control at each time point whereas in Sham, the level was elevated in 6 and $24 \mathrm{~h}$ only.

In platelets, the level of total Cer decreased dramatically in Infarct in 1 and $6 \mathrm{~h}$ and returned partially to the control in $24 \mathrm{~h}$. In Sham the level of total Cer in 1 and $6 \mathrm{~h}$ was also reduced though to much lesser degree than in Infarct. 
Table 5 Effect of myocardial infarction on the level of individual ceramides in platelets (pmolg/mg protein) of the rat

Total level of ceramide is presented at the Table 2 and the Fig. 5

Values are mean \pm SD

$I$ infarct, $S$ sham operated $N=8$ with the exception of sham $1 \mathrm{~h}$ where $N=7$

${ }^{\mathrm{a}} p<0.05$ as compared to the control

${ }^{\mathrm{b}} p<0.05$ as compared to the respective value in the Sham group

\begin{tabular}{llcccccc}
\hline Ceramide & Control & I h & \multicolumn{3}{c}{$6 \mathrm{~h}$} & $24 \mathrm{~h}$ \\
\hline $\mathrm{C} 14$ & $0.92 \pm 0.08$ & $\mathrm{I}$ & $0.26 \pm 0.11^{\mathrm{a}, \mathrm{b}}$ & $\mathrm{I}$ & $0.59 \pm 0.45$ & $\mathrm{I}$ & $0.78 \pm 0.06$ \\
& & $\mathrm{~S}$ & $0.93 \pm 0.10$ & $\mathrm{~S}$ & $0.78 \pm 0.04$ & $\mathrm{~S}$ & $0.78 \pm 0.06$ \\
$\mathrm{C} 16$ & $74.66 \pm 9.96$ & $\mathrm{I}$ & $11.42 \pm 0.48^{\mathrm{a}, \mathrm{b}}$ & $\mathrm{I}$ & $29.93 \pm 4.33^{\mathrm{a}, \mathrm{b}}$ & $\mathrm{I}$ & $57.45 \pm 6.41^{\mathrm{a}}$ \\
& & $\mathrm{S}$ & $82.17 \pm 7.40$ & $\mathrm{~S}$ & $59.12 \pm 7.32^{\mathrm{a}}$ & $\mathrm{S}$ & $54.84 \pm 3.31^{\mathrm{a}}$ \\
$\mathrm{C} 18$ & $9.74 \pm 0.78$ & $\mathrm{I}$ & $3.33 \pm 0.25^{\mathrm{a}, \mathrm{b}}$ & $\mathrm{I}$ & $2.65 \pm 0.37^{\mathrm{a}, \mathrm{b}}$ & $\mathrm{I}$ & $6.89 \pm 0.81^{\mathrm{a}}$ \\
& & $\mathrm{S}$ & $8.66 \pm 1.17$ & $\mathrm{~S}$ & $6.54 \pm 0.58^{\mathrm{a}}$ & $\mathrm{S}$ & $6.36 \pm 0.57^{\mathrm{a}}$ \\
$\mathrm{C} 18: 1$ & $1.33 \pm 0.16$ & $\mathrm{I}$ & $0.92 \pm 0.15^{\mathrm{a}, \mathrm{b}}$ & $\mathrm{I}$ & $0.71 \pm 0.05^{\mathrm{a}, \mathrm{b}}$ & $\mathrm{I}$ & $0.71 \pm 0.04^{\mathrm{a}, \mathrm{b}}$ \\
& & $\mathrm{S}$ & $1.32 \pm 0.09$ & $\mathrm{~S}$ & $0.89 \pm 0.09^{\mathrm{a}}$ & $\mathrm{S}$ & $0.89 \pm 0.11^{\mathrm{a}}$ \\
$\mathrm{C} 20$ & $3.31 \pm 0.25$ & $\mathrm{I}$ & $1.97 \pm 0.17^{\mathrm{a}}$ & $\mathrm{I}$ & $1.52 \pm 0.20^{\mathrm{a}}$ & $\mathrm{I}$ & $1.68 \pm 0.40^{\mathrm{a}}$ \\
& & $\mathrm{S}$ & $2.38 \pm 0.32^{\mathrm{a}}$ & $\mathrm{S}$ & $1.35 \pm 0.10^{\mathrm{a}}$ & $\mathrm{S}$ & $1.35 \pm 0.42^{\mathrm{a}}$ \\
$\mathrm{C} 22$ & $21.06 \pm 2.22$ & $\mathrm{I}$ & $10.45 \pm 0.58^{\mathrm{a}, \mathrm{b}}$ & $\mathrm{I}$ & $9.00 \pm 3.28^{\mathrm{a}}$ & $\mathrm{I}$ & $15.43 \pm 1.53^{\mathrm{a}, \mathrm{b}}$ \\
& & $\mathrm{S}$ & $15.59 \pm 2.43^{\mathrm{a}}$ & $\mathrm{S}$ & $11.90 \pm 1.22^{\mathrm{a}}$ & $\mathrm{S}$ & $11.41 \pm 1.09^{\mathrm{a}}$ \\
$\mathrm{C} 24$ & $81.68 \pm 10.32$ & $\mathrm{I}$ & $36.61 \pm 3.66^{\mathrm{a}, \mathrm{b}}$ & $\mathrm{I}$ & $30.30 \pm 4.26^{\mathrm{a}, \mathrm{b}}$ & $\mathrm{I}$ & $54.30 \pm 5.46^{\mathrm{a}}$ \\
& & $\mathrm{S}$ & $75.37 \pm 7.54$ & $\mathrm{~S}$ & $60.30 \pm 5.94^{\mathrm{a}}$ & $\mathrm{S}$ & $59.53 \pm 4.48^{\mathrm{a}}$ \\
$\mathrm{C} 24: 1$ & $23.98 \pm 2.59$ & $\mathrm{I}$ & $8.79 \pm 1.03^{\mathrm{a}, \mathrm{b}}$ & $\mathrm{I}$ & $11.42 \pm 1.42^{\mathrm{a}, \mathrm{b}}$ & $\mathrm{I}$ & $17.74 \pm 0.60^{\mathrm{a}}$ \\
& & $\mathrm{S}$ & $24.22 \pm 2.87$ & $\mathrm{~S}$ & $15.89 \pm 1.37^{\mathrm{a}}$ & $\mathrm{S}$ & $17.13 \pm 1.14^{\mathrm{a}}$ \\
\hline
\end{tabular}
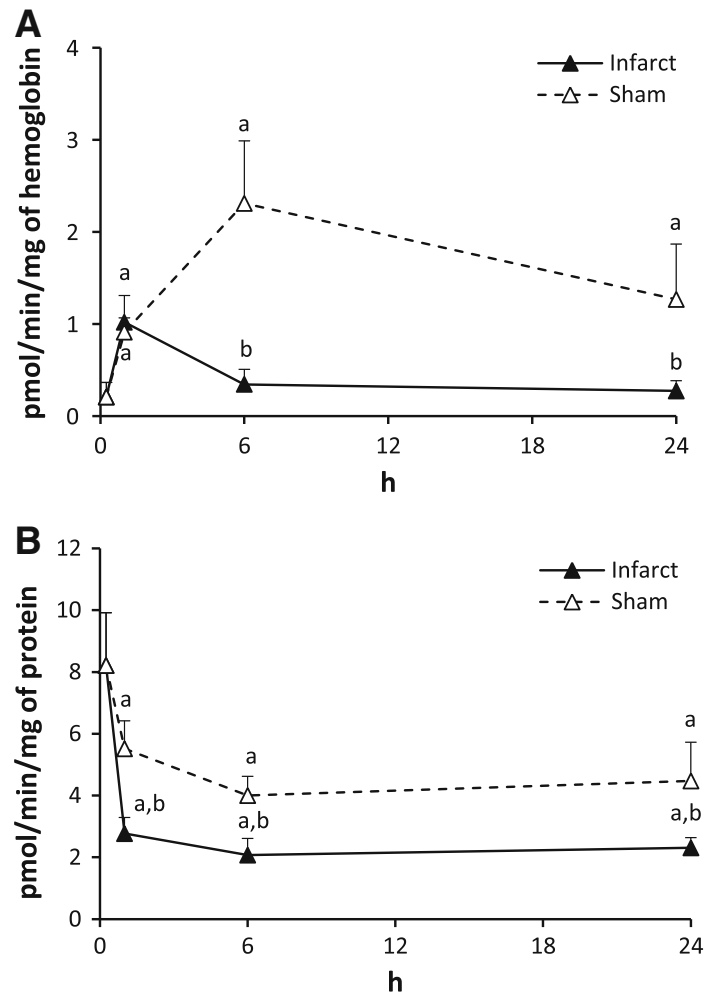

Fig. 7 The impact of myocardial infarction (black triangles) or sham operation (open triangles) on the activity of sphingosine kinase (SK) in erythrocytes (A) and platelets (B). Black vertical bars represent SD ( $n=6$ per group). $a p<0.05$ as compared to the control, $b p<0.05$ as compared to appropriate sham group

Individual ceramides (Tables 3, 4, 5) Because of a great number and diversity of data, the levels of individual ceramides are shown in the Tables 3, 4, 5 and are not presented in detail here.

\section{Activity of sphingosine kinase (SK, Fig. 7)}

In erythrocytes of Infarct, SK activity increased in $1 \mathrm{~h}$ and it returned to the control, thereafter. In Sham, SK activity was elevated at each time point studied.

In platelets, the activity of SK was reduced in $1 \mathrm{~h}$ in both groups and remained further stable. The values in Infarct were lower from the respective values in Sham.

\section{Effect of ligation of the femoral artery}

Plasma (Fig. 8). The levels of SPH and S1P were reduced but remained higher from the respective value after ligation of the left coronary artery. The level of DHS, DHS1P and total ceramide remained stable.

Erythrocytes (Fig. 9). The level of SPH and DHS decreased whereas the level of S1P and DHS1P increased compared both to the respective control value and after ligation of the coronary artery. The level of total ceramide remained stable.

Platelets (Fig. 10). The levels of SPH and DHS increased whereas the levels of S1P, DHS1P and total ceramide remained stable.

The levels of individual ceramides in each blood compartment are given in the Table 6 .

Activity of sphingosine kinase (Fig. 11). Ligation of the artery increased the SK activity in erythrocytes and had no significant effect on the activity in the platelets. 
Fig. 8 The impact of ligation of the left coronary artery, ligation of the femoral artery and second anesthesia on the plasma level of sphingosine (A) dihydrosphingosine (B), sphingosine-1-phosphate (C), dihydrosphingosine-1phosphate (D) and ceramide (E). The blood samples were taken $6 \mathrm{~h}$ after ligation of the arteries and after second anesthesia applied in $6 \mathrm{~h}$ after the first one. Values represent mean \pm SD. $a p<0.05$ as compared to the control
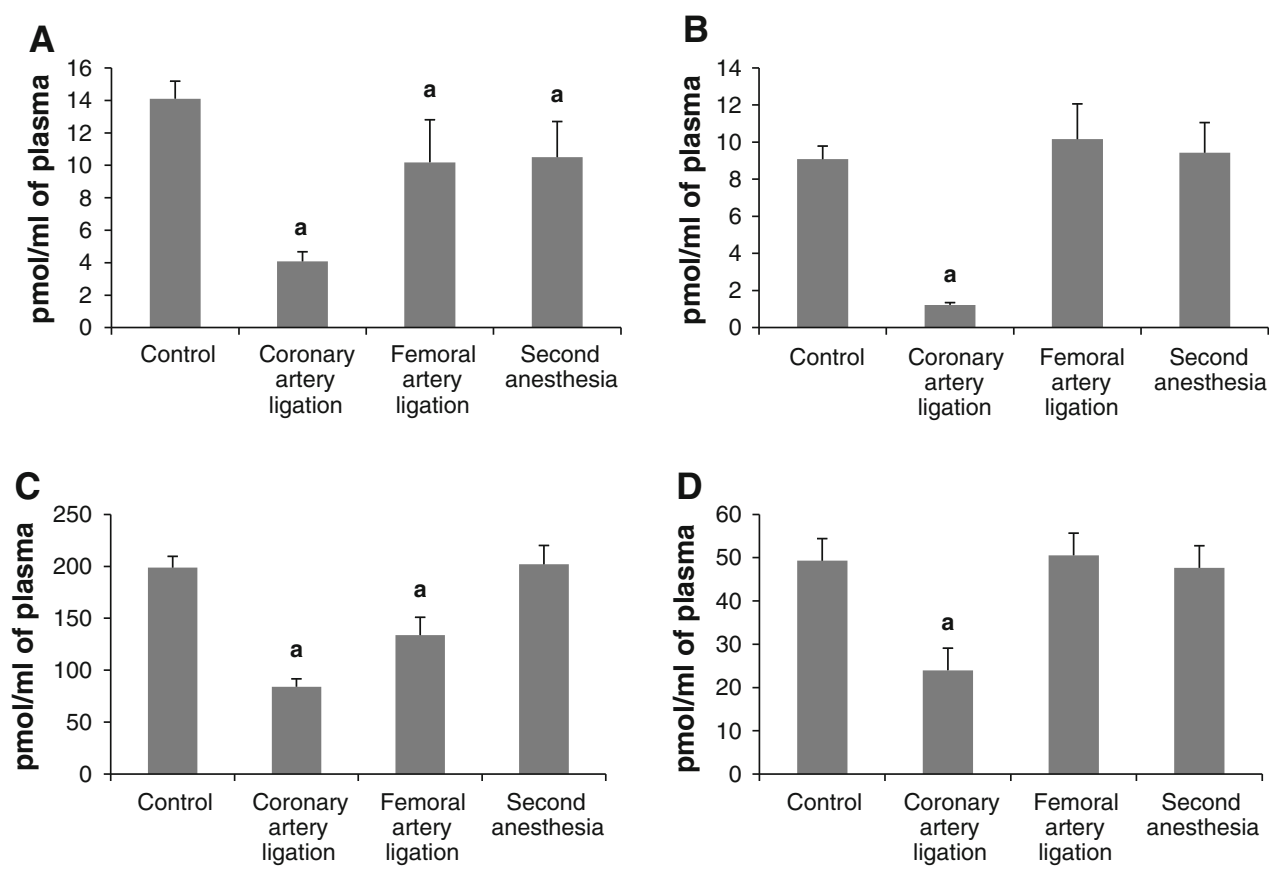

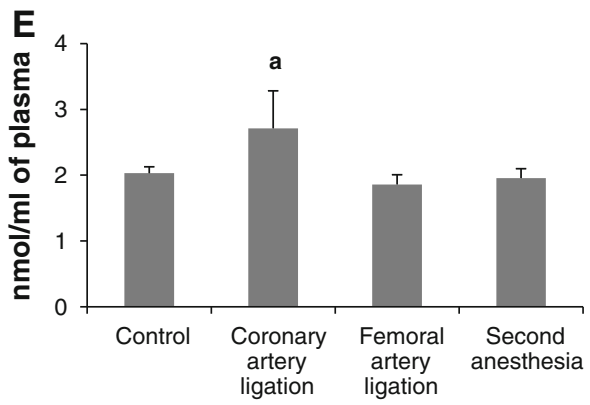

\section{Effect of anesthesia}

Plasma (Fig 8). The anesthesia reduced the level of SPH whereas the other examined variables remained unchanged as compared to the respective control values.

Erythrocytes (Fig. 9) and platelets (Fig. 10). The procedure did not affect the level of either examined sphingolipid.

The levels of individual ceramides in each blood compartment are given in the Table 6.

\section{Discussion}

The results obtained in the present study in rats clearly show that the myocardial infarction produces profound changes in metabolism of examined sphingolipids not only in the plasma but also in erythrocytes and platelets. Moreover, the direction and the size of changes depend both on the species of sphingolipid and the blood compartment. The plasma level of S1P was reduced after the infarction. It is in agreement with previously reported data in humans [30]. It should be noted that, at present, there are no data available on in vivo regulation of behavior of sphingolipids in the plasma. Therefore, it would be premature to hypothesize about a mechanism of the changes in the plasma sphingolipids presented in our study. The enzyme sphingosine kinase (SK) catalyzes phosphorylation of sphingosine to S1P and DHS to DHS1P $[9,23,47]$. The plasma activity of sphingosine kinase is rather low [52]. With the method used in this study [53] the values of the activity of SK in the rat plasma were merely on the level of detection and they are not included in the manuscript. Therefore, changes in the activity in plasma SK after the infarction are not likely to contribute to the reduction in the level of plasma S1P.

The reduction in the plasma level of S1P in Infarct was accompanied by its elevation in erythrocytes and profound reduction in the platelets. Erythrocytes and platelets were shown to possess the enzyme sphingosine kinase and thus 
Fig. 9 The impact of ligation of the left coronary artery, ligation of the femoral artery and second anesthesia on the level of sphingosine

(A) dihydrosphingosine (B), sphingosine-1-phosphate (C), dihydrosphingosine-1-

phosphate (D) and ceramide

(E) in erythrocytes. The blood samples were taken $6 \mathrm{~h}$ after ligation of the arteries and after second anesthesia applied in $6 \mathrm{~h}$ after the first one. Values represent mean $\pm \mathrm{SD}$. a $p<0.05$ as compared to the control
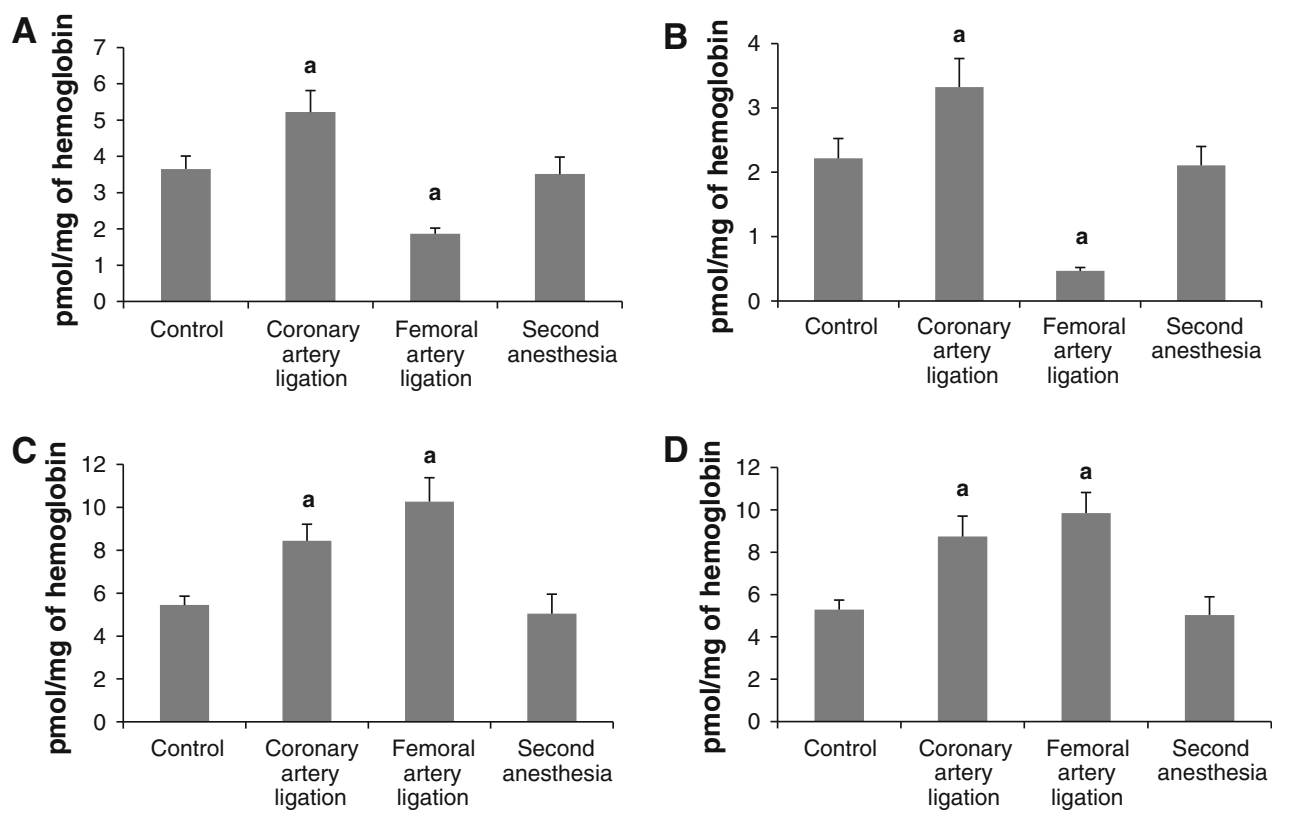

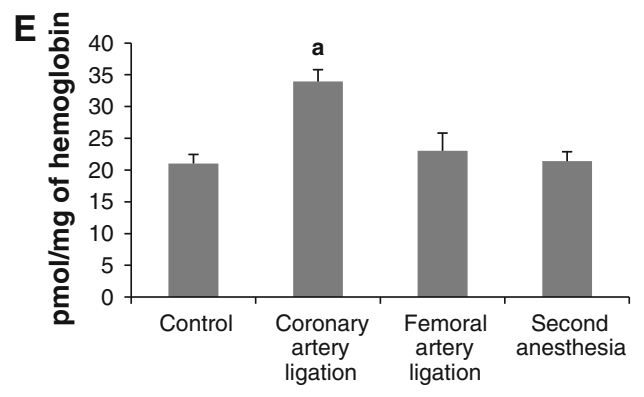

are able to synthetize S1P from sphingosine [9, 23, 47]. S1P is catabolized by two enzymes: phosphohydrolase which dephosphorylates the compound and S1P lyase which irreversibly catabolizes it to hexadecenal and phosphoethanolamine. The erythrocytes are the only known cells not to have both enzymes and thus may be considered as the "ideal" store of the compound [23]. In humans, the level of S1P in a single platelet is about $9 \times$ higher that in the erythrocyte. However, in a unit of blood the amount of S1P in erythrocytes is much higher than in the platelets which is due to much higher number of erythrocytes as compared to the number of platelets [23]. SK activity in erythrocytes was elevated in $1 \mathrm{~h}$ after ligation of the artery and returned to the control value, thereafter. In Sham it was elevated at each time point (Fig. 7). The elevation in SK activity would, at least partially, contribute to elevation of S1P in the cells. Hänel et al. [19] showed that reduction in the plasma/erythrocytes ratio reduces release of S1P. We found no change in the hematocrit, the number of erythrocytes and platelets, and other blood variables after the infarction (Table 1). This excludes a contribution of changes in the cell factor to the level of the examined sphingolipids in the plasma or the erythrocytes during the myocardial ischemia. Erythrocytes were shown to release S1P into plasma. Also, they take up S1P from serum or plasma-free medium [19]. However, since the level of S1P in erythrocytes increased after the infraction, release of the compound into plasma was probably inhibited or at least diminished. It should be added that the mechanism of transport of S1P across the plasma membranes hasn't yet been recognized. It was hypothesized that ATP cassette transporters are involved in the process [32, 39, 43].

Platelets do not contain S1P lyase but they contain S1P phosphohydrolase $[23,58]$. However, it is unlikely that the activity of the latter enzyme increased after the infarction to such an extent that it could account for such a deep reduction in the content of S1P. Human platelets were shown to release S1P upon stimulation [57, 58]. Mouse platelets do not contain S1P but they contain and release DHS1P upon stimulation [14]. It should be stressed that the content of S1P (and DHS1P) in the platelets behave quite opposite to the content in the erythrocytes thus suggesting fundamentally different mechanisms operating in the two type of cells after the infarction. In the platelets, SK 
Fig. 10 The impact of ligation of the left coronary artery, ligation of the femoral artery and second anesthesia on the level of sphingosine

(A) dihydrosphingosine (B), sphingosine-1-phosphate (C), dihydrosphingosine-1-

phosphate (D) and ceramide

(E) in platelets. The blood samples were taken $6 \mathrm{~h}$ after ligation of the arteries and after second anesthesia applied in $6 \mathrm{~h}$ after the first one. Values represent mean $\pm \mathrm{SD}$. a $p<0.05$ as compared to the control
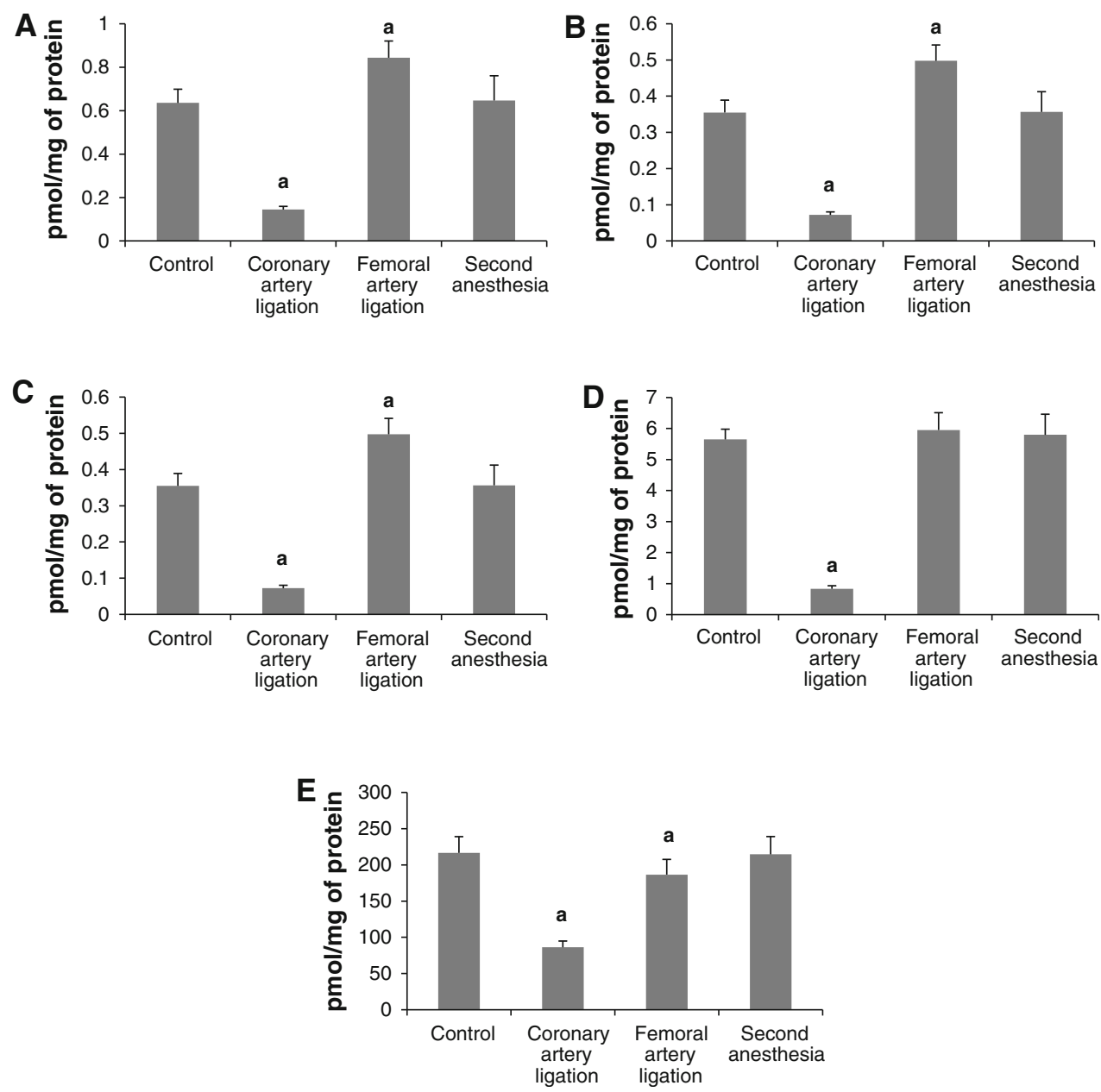

activity was reduced in both groups and the reduction in the Infarct was more pronounced than in Sham. Therefore, the reduction in the S1P (and DHS1P) level in platelets in Infarct could be a consequence of reduction of the synthesis of the two compounds. Increased release of the compounds in the infarct should also be taken into account. The coexistence of reduced SK activity and stable level of S1P (and DHS1P) in the platelets in Sham would rather suggest a reduction in release of the compounds.

It is an open question whether the effects of ligation of the coronary artery are specific or whether they can be mimicked by ligation of a peripheral artery. To check this possibility we carried out determinations in the level of sphingolipids in the blood compartments after ligation of the femoral artery. As it can be seen from the Figs. 8, 9, 10 the results obtained differ markedly from the respective data after ligation of the coronary artery. The most striking difference is observed in platelets where the levels of S1P, SPH and DHS increased whereas the level of DHS1P remained stable. The activity of SK in erythrocytes was elevated and this would explain the elevation in S1P level after ligation of the artery. In platelets, the enzyme activity was also elevated but did not reach the level of significance. This degree of elevation in SK activity in the platelets could not probably account solely for elevation in the level of S1P.

The comparison of the results after ligation of the coronary and femoral artery clearly indicates that the exclusion of the each artery affect blood sphingolipid metabolism in a specific way. However, we found no data in the literature to explain the mechanism responsible for the described differences. One may only speculate that ligation of the coronary artery was a much stronger stress than ligation of the femoral artery (see below). Vascular endothelial cells release S1P into plasma. However, neither the rate of secretion nor its extent is recognized, so far $[1,29]$. The results obtained after ligation of the femoral artery rather exclude an involvement of endothelium in reduction in the plasma $\mathrm{S} 1 \mathrm{P}$ after ligation of the coronary artery. It is interesting that sham surgery also produced numerous changes in the level of the examined compounds. At present, there is no reliable data for explanation of the 
Table 6 Effect of second anaesthesia (A) and ligation of femoral artery (F) on the level of individual ceramides in different blood compartments of the rat

\begin{tabular}{|c|c|c|c|c|c|c|}
\hline \multirow{2}{*}{$\frac{\text { Ceramide }}{\mathrm{C} 14}$} & \multicolumn{2}{|c|}{ Plasma (pmol/ml) } & \multicolumn{2}{|c|}{ Erythrocytes (pmol/mg of hemoglobin) } & \multicolumn{2}{|c|}{ Platelets ( $\mathrm{pmol} / \mathrm{mg}$ of protein) } \\
\hline & $\mathrm{C}$ & $220.7 \pm 17.7$ & $\mathrm{C}$ & $0.068 \pm 0.006$ & $\mathrm{C}$ & $0.924 \pm 0.084$ \\
\hline & A & $235.8 \pm 29.6$ & A & $0.074 \pm 0.013$ & A & $0.946 \pm 0.084$ \\
\hline & $\mathrm{F}$ & $210.6 \pm 23.6$ & $\mathrm{~F}$ & $0.061 \pm 0.006$ & $\mathrm{~F}$ & $0.755 \pm 0.117$ \\
\hline \multirow[t]{3}{*}{ C16 } & $\mathrm{C}$ & $278.6 \pm 20.4$ & $\mathrm{C}$ & $5.23 \pm 0.41$ & $\mathrm{C}$ & $74.7 \pm 10.0$ \\
\hline & A & $265.4 \pm 29.3$ & A & $5.11 \pm 0.72$ & A & $79.0 \pm 13.9$ \\
\hline & $\mathrm{F}$ & $298.0 \pm 62.1$ & $\mathrm{~F}$ & $5.51 \pm 0.83$ & $\mathrm{~F}$ & $62.8 \pm 14.0$ \\
\hline \multirow[t]{3}{*}{ C18 } & $\mathrm{C}$ & $3.56 \pm 0.30$ & $\mathrm{C}$ & $0.194 \pm 0.016$ & $\mathrm{C}$ & $9.74 \pm 0.78$ \\
\hline & A & $3.68 \pm 0.55$ & A & $0.200 \pm 0.017$ & A & $9.14 \pm 0.51$ \\
\hline & $\mathrm{F}$ & $4.66 \pm 0.56^{\mathrm{a} .}{ }^{\mathrm{b}}$ & $\mathrm{F}$ & $0.232 \pm 0.023^{\mathrm{a}}$ & $\mathrm{F}$ & $9.46 \pm 1.21$ \\
\hline \multirow[t]{3}{*}{ C18:1 } & $\mathrm{C}$ & $4.16 \pm 0.30$ & $\mathrm{C}$ & $0.082 \pm 0.007$ & $\mathrm{C}$ & $1.34 \pm 0.17$ \\
\hline & A & $4.39 \pm 0.70$ & A & $0.090 \pm 0.011$ & A & $1.39 \pm 0.09$ \\
\hline & $\mathrm{F}$ & $4.29 \pm 0.74$ & $\mathrm{~F}$ & $0.078 \pm 0.006$ & $\mathrm{~F}$ & $1.24 \pm 0.18$ \\
\hline \multirow[t]{3}{*}{$\mathrm{C} 20$} & $\mathrm{C}$ & $4.81 \pm 0.46$ & $\mathrm{C}$ & $0.103 \pm 0.009$ & $\mathrm{C}$ & $3.31 \pm 0.25$ \\
\hline & A & $4.46 \pm 0.94$ & A & $0.100 \pm 0.015$ & A & $3.31 \pm 0.84$ \\
\hline & $\mathrm{F}$ & $5.22 \pm 0.47$ & $\mathrm{~F}$ & $0.125 \pm 0.014$ & $\mathrm{~F}$ & $1.97 \pm 0.39^{\mathrm{a}, \mathrm{b}}$ \\
\hline \multirow[t]{3}{*}{$\mathrm{C} 22$} & $\mathrm{C}$ & $92.7 \pm 8.21$ & $\mathrm{C}$ & $1.89 \pm 0.07$ & $\mathrm{C}$ & $21.0 \pm 2.2$ \\
\hline & A & $90.0 \pm 8.53$ & A & $2.38 \pm 0.20^{\mathrm{a}}$ & A & $18.2 \pm 1.5$ \\
\hline & $\mathrm{F}$ & $83.2 \pm 7.20$ & $\mathrm{~F}$ & $2.08 \pm 0.31$ & $\mathrm{~F}$ & $16.4 \pm 1.6^{\mathrm{a}}$ \\
\hline \multirow[t]{3}{*}{$\mathrm{C} 24$} & $\mathrm{C}$ & $1207.1 \pm 83.1$ & $\mathrm{C}$ & $10.6 \pm 1.16$ & $\mathrm{C}$ & $81.6 \pm 10.3$ \\
\hline & A & $1166.6 \pm 111.5$ & A & $10.3 \pm 1.25$ & A & $79.0 \pm 10.9$ \\
\hline & $\mathrm{F}$ & $1054.6 \pm 142.7$ & $\mathrm{~F}$ & $11.5 \pm 2.01$ & $\mathrm{~F}$ & $76.6 \pm 9.6$ \\
\hline \multirow[t]{3}{*}{ C24:1 } & $\mathrm{C}$ & $217.8 \pm 8.37$ & $\mathrm{C}$ & $2.84 \pm 0.19$ & $\mathrm{C}$ & $24.0 \pm 2.6$ \\
\hline & A & $185.2 \pm 22.5$ & A & $3.14 \pm 0.63$ & A & $23.7 \pm 3.0$ \\
\hline & $\mathrm{F}$ & $197.7 \pm 15.7$ & $\mathrm{~F}$ & $3.46 \pm 0.33$ & $\mathrm{~F}$ & $17.3 \pm 2.5^{\mathrm{a}, \mathrm{b}}$ \\
\hline
\end{tabular}

The blood samples were taken $6 \mathrm{~h}$ after ligation of the femoral artery and after second anaesthesia applied in $6 \mathrm{~h}$ after the first one

The total level of ceramide is presented at the Figs. 8, 9, 10

Values are mean $\pm \mathrm{SD}$

$C$ control, $A$ second anaesthesia, $F$ ligation of femoral artery

$N=8$

${ }^{\mathrm{a}} p<0.05$ as compared to the control

${ }^{\mathrm{b}} p<0.05$ as compared to the respective value in the second anaesthesia group

phenomenon. However, it is well known that a number of stress factors, cytokines and steroid hormones affect sphingolipid metabolism [21, 41]. We examined possible role of second anesthesia ( $6 \mathrm{~h}$ after the first one) and found that it did not affect the level of either sphingolipid (Figs. 8, 9, 10). It may be presumed that thoracotomy and exteriorization of the heart in the sham group was a stress strong enough to produce the observed changes. When we take into account the data in Infarct, in Sham and the data obtained after ligation of the femoral artery we conclude that the sphingolipid signaling system in the blood compartments is very sensitive to different factors. A mechanism creating the changes certainly warrants further investigation. The consequence of the reduction in the plasma S1P concentration after myocardial infarction is not known. The left coronary artery was tightened up permanently so that the blood-borne S1P could not reach the infarcted area. However, the reduction in the plasma S1P concentration may result in reduction of its cardioprotective action in the surrounding area with reduced blood flow as well the intact area.

DHS1P is present in human plasma [2, 19]. It was also reported to be present in mice but not in human erythrocytes and in platelets of both species [14]. We found it in each blood compartment of the rat examined. Its concentration in the mice plasma is much lower than the concentration of S1P [2] and it was presently confirmed in the rat. After the infarction, the level of DHS1P follows 

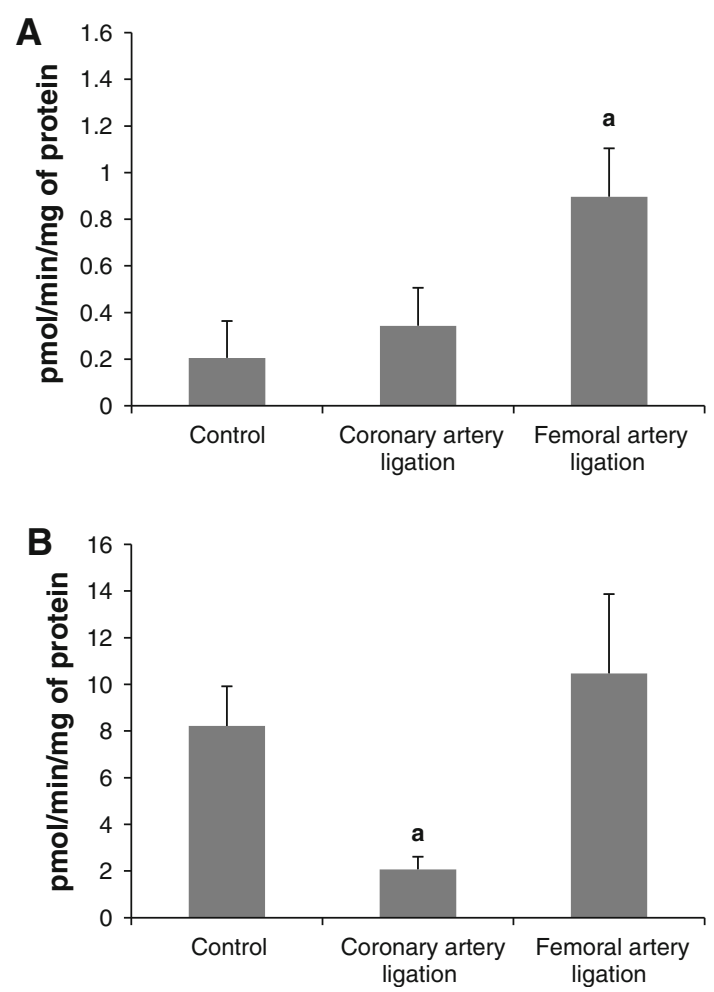

Fig. 11 The impact of ligation of the left coronary artery, and ligation of the femoral artery on the activity of sphingosine kinase (SK) in erythrocytes (A) and platelets (B). The blood samples were taken $6 \mathrm{~h}$ after ligation of the arteries.Values represent mean $\pm \mathrm{SD}$. a $p<0.05$ as compared to the control

changes in the concentration of S1P in each compartment. DHS1P is formed by phosphorylation of dihydrosphingosine (sphinganine) by sphingosine kinase. It also binds to S1P receptors [22]. Its physiological role hasn't yet been elucidated. It is, therefore, impossible to evaluate functional meaning of the changes in the level of DHS1P after the infarction. However, this indicates that metabolism of the compound in the blood is strongly influenced by the myocardial infarction.

Dihydrosphingosine (DHS) is a precursor of ceramide on its de novo synthesis pathway and sphingosine (SPH) is a product of deacylation of ceramide [17, 41]. DHS was found in minute amounts in mouse plasma and platelets. In humans, it was present only in plasma while sphingosine was present in each compartment [14]. We also previously reported the presence of DHS and SPH in human plasma [31]. Presently, a dramatic reduction in the plasma concentration of both compounds after the infarction was demonstrated. This is in contrast with the data obtained previously in humans where the concentration of the two intermediates remained stable after the infarction [31]. It remains an open question whether this results from interspecies differences or of treatment in humans. SPH (and probably DHS) crosses the plasma membrane [11].
However, the source of the two compounds in plasma is unknown so that it is impossible to speculate on a cause of a reduction in their liberation into plasma after the infarction. The reduction in the plasma concentration of DHS and SPH was accompanied by elevated levels in erythrocytes and profound reduction in their levels in platelets. It is tempting to speculate that increased amounts of DHS and SPH were taken up by erythrocytes early after the infarction what is reflected by elevation in their level in erythrocytes. Thereafter, these precursors were phosphorylated to S1P (and DHS1P, respectively) what resulted in the reduction of their levels in the cells. In platelets, the bases were likely phosphorylated and the phosphorylated derivatives were subsequently released into the plasma. Another possibility is that DHS and SPH were released from the platelets into plasma from where they were taken up by erythrocytes. At present, there is no data on the action of DHS on the heart. As was mentioned in the introduction, $\mathrm{SPH}$, in a low dose, is cardioprotective whereas in a high dose it is cardiotoxic [56]. A reduction in its plasma concentration would likely be beneficial for the undernourished area of the heart.

Ceramide (CER) is a key compound on crossroads of sphingolipid metabolism. In the cell, it is synthetized de novo from serine and palmitoyl $\mathrm{CoA}$ in a reaction catalyzed by the enzyme serine palmitoyl transferase and it is formed from sphingomyelin by the action of the enzyme sphingomyelinase [17, 41]. In humans, C24-ceramide is the principal ceramide in plasma and platelets and the amount of C24:1 ceramide is much less abundant. In erythrocytes, the level of both ceramides is almost equal. In mice, C24-1 ceramide constitutes about half of all ceramides in plasma, less than a half in erythrocytes and about $2 / 3$ in platelets [14]. Activation of isolated mouse platelets with thrombin results in severalfold reduction in C24-ceramide and considerable reduction in $\mathrm{C} 24: 1$-ceramide. It has been suggested that the reduction was due to increased hydrolysis by intracellular ceramidase [14]. It should be added, however, that in another study stimulation of platelets did not affect the activity of the enzyme [42]. In our study, C24-ceramide was also the most abundant ceramide in each examined blood compartment. The infarction elevated the level of total CER in plasma and erythrocytes but reduced it markedly in platelets. In the latter case it resembles the data after stimulation of platelets [14]. Interestingly, the plasma CER concentration was stable after the infarction in humans [31]. Regulation of the level of CER in plasma and the blood cells remains to be recognized. Plasma CER is synthetized in the liver and exported to plasma with lipoproteins. Acid sphingomyelinase and neutral ceramidase are also present in the extracellular space and thus ceramide can be formed and hydrolyzed there. However, the amount of CER formed 
and removed in the extracellular space is rather small and thus it does not contribute much to the plasma level of this compound [46]. At present, there is also no data which would suggest the mechanism responsible for elevation in the level of CER in erythrocytes after the infarction. As it can be seen in Tables 3, 4, 5, there are numerous changes in behavior in the content of individual ceramides in each examined blood compartment. Neither the direction nor the degree of the changes creates a uniform picture which would allow for interpretation of the individual data. However, it should be mentioned that our knowledge on a mechanism of diversified behavior of particular ceramides or a meaning of it is rather limited. Therefore, this problem will not be further discussed here. We should, at least now, keep in mind that such changes are produced by myocardial infarction.

CER is the intracellular second messenger. It is very active biologically [4, 7, 41]. Naturally occurring long chain ceramides in the plasma cannot cross the plasma membrane. Therefore, one cannot define possible consequence of acute changes in their plasma level.

To summarize, we have found, for the first time, that the experimental heart infarction in the rat produces numerous and profound changes in metabolism of sphingolipids in the plasma, platelets and erythrocytes. It manifests with a reduction in the level of plasma DHS, SPH, S1P and DHS1P and elevation in the level of total CER. In erythrocytes, there was a sharp elevation in the level of SPH and DHS in 1 and $6 \mathrm{~h}$ and a reduction in $24 \mathrm{~h}$ after the infarction whereas the level of S1P, DHS1P and total ceramide gradually increased. In platelets, the level of the examined compounds profoundly decreased in 1 and $6 \mathrm{~h}$ and partially normalized in $24 \mathrm{~h}$ after the infarction.

Acknowledgments This study was supported by the Medical University of Bialystok, grant number 123-18808 and 3-18950. Dr. Justyna Marciniak is greatly acknowledged for invaluable assistance in determination of the ischemic area.

Open Access This article is distributed under the terms of the Creative Commons Attribution License which permits any use, distribution, and reproduction in any medium, provided the original author(s) and the source are credited.

\section{References}

1. Ancellin N, Colmont C, Su J, Li Q, Mittereder N, Chae SS, Stefansson S, Liau G, Hla T (2002) Extracellular export of sphingosine kinase-1 enzyme. Sphingosine 1-phosphate generation and the induction of angiogenic vascular maturation. J Biol Chem 277:6667-6675. doi:10.1074/jbc.M102841200

2. Andréani P, Gräler MH (2006) Comparative quantification of sphingolipids and analogs in biological samples by high-performance liquid chromatography after chloroform extraction. Anal Biochem 358:239-246. doi:10.1016/j.ab.2006.08.027
3. Argaud L, Prigent A-F, Chalabreysse L, Loufouat J, Lagarde M, Ovize M (2004) Ceramide in the antiapoptotic effect of ischemic preconditioning. Am J Physiol Heart Circ Physiol 286:H246H251. doi:10.1152/ajpheart.00638.2003

4. Bartke N, Hannun YA (2009) Bioactive sphingolipids: metabolism and function. J Lipid Res S91-S96. doi:10.1194/jlr.R800080JLR200

5. Beręsewicz A, Dobrzyń A, Górski J (2002) Accumulation of specific ceramides in ischemic/reperfused ceramides; effect of ischemic preconditioning. J Physiol Pharmacol 53:371-382

6. Bielawska AE, Shapiro JP, Jiang L, Melkonyan HS, Piot C, Wolfe C, Tomei D, Hannun Y, Umansky SR (1997) Ceramide is involved in triggering of cardiomyocyte apoptosis induced by ischemia and reperfusion. Am J Pathol 151:1257-1263

7. Bikman BT, Summers SA (2011) Ceramides as modulators of cellular and whole-body metabolism. J Clin Invest 121:4222-4230. doi:10.1172/JCI57144

8. Błachnio-Zabielska AU, Persson X-MT, Koutsari C, Zabielski P, Jensen MD (2012) An LC/MS/MS method for measuring the in vivo incorporation of plasma free fatty acids into intramyocellular ceramides in humans. Rapid Commun Mass Spectrom 26:1134-1140. doi:10.1002/rcm.6216

9. Bode C, Sensken S-C, Peest U, Beutel G, Thol F, Levkau B, Li Z, Bittman R, Huang T, Tölle M, Giet M, Gräler MH (2010) Erythrocytes serve as a reservoir for cellular and extracellular sphingosine 1-phosphate. J Cell Biochem 109:1232-1243. doi:10.1002/jcb.22507

10. Boengler K, Hilfiker-Kleiner D, Drexler H, Heusch G, Schulz R (2008) The myocardial JAK/STAT pathway: from protection to failure. Pharmacol Therapeut 120:172-185. doi:10.1016/j. pharmthera.2008.08.002

11. Cavalli AM, Ligutti JA, Gellings NM, Castro E, Page TM, Klepper RE, Palade PT, McNutt WT, Sabbadini RA (2002) The role of $\mathrm{TNF} \alpha$ and sphingolipid signaling in cardiac hypoxia: evidence that cardiomyocytes release $\mathrm{TNF} \alpha$ and sphingosine. Basic Appl Myol 12:167-175

12. Cordis GA, Yoshida T, Das DK (1998) HPTLC analysis of sphingomyelin, ceramide and sphingosine in ischemic/reperfused rat heart. J Pharm Biomed Anal 16:1189-1193. doi:10.1016/ S0731-7085(97)00260-4

13. Cui J, Engelman RM, Maulik N, Das DK (2004) Role of ceramide in ischemic preconditioning. J Am Coll Surg 198:770-777. doi:10.1016/j.jamcollsurg.2003.12.016

14. Dahm F, Nocito A, Bielawska A, Lang KS, Georgiev P, Asmis LM, Bielawski J, Madon J, Hannun YA, Clavien PA (2006) Distribution and dynamic changes of phospholipids in blood in response to platelet activation. J Thromb Haemost 4:2704-2709. doi:10.1111/j.1538-7836.2006.02241.x

15. Frias MA, James RW, Gerber-Wicht Ch, Lang U (2009) Native and reconstitute HDL activate Stat 3 in ventricular cardiomyocytes via ERK1/2: role of sphingosine-1-phosphate. Cardiovasc Res 82:313-323. doi:10.1093/cvr/cvp024

16. Fujio Y, Nguyen T, Wencker D, Kitsis RN, Walsh K (2000) Akt promotes survival of cardiomyocytes in vitro and protects against ischemia-reperfusion injury in mouse heart. Circulation 101:660-667. doi:10.1161/01.CIR.101.6.660

17. Gault CR, Obeid LM, Hannun YA (2010) An overview of sphingolipid metabolism: from synthesis to breakdown. Adv Exp Med Biol 688:1-23

18. Gomez L, Paillard M, Price M, Chen Q, Teixeira G, Spiegel S, Lesnefsky EJ (2011) A novel role for mitochondrial sphingosine1-phosphate produced by sphingosine kinase-2 in PTP-mediated cell survival during cardioprotection. Basic Res Cardiol 106:1341-1353. doi:10.1007/s00395-011-0223-7

19. Hänel $P$, Andréani $P$, Gräler MH (2007) Erythrocytes store and release sphingosine 1-phosphate in blood. FASEB J 21:1202-1209. doi:10.1096/fj.06-7433com 
20. Heusch G, Boengler K, Schultz R (2008) Cardioprotection: nitric oxide, protein kinases, and mitochondria. Circulation 118:19151919. doi:10.1161/CIRCULATIONAHA.108.805242

21. Huwiler A, Kotler T, Pfeilschifter J, Sandhoff K (2000) Physiology and pathophysiology of sphingolipid metabolism and signaling. Biochem Biophys Acta 1485:63-69. doi:10.1016/S138812-1981(00)0004

22. Inagaki Y, Pham TT, Fujiwara Y, Kohono T, Osborne DA, Igarashi Y, Tigyi G, Parrill AL (2005) Sphingosine 1-phosphate analogue recognition and selectivity at S1P4 within the endothelial differentiation gene family of receptors. Biochem $\mathbf{J}$ 389:187-195. doi:10.1042/BJ20050046

23. Ito K, Anada Y, Tani M, Ikeda M, Sano T, Kihara A, Igarashi Y (2007) Lack of sphingosine 1-phosphate degrading enzymes in erythrocytes. Biochem Biophys Res Commun 357:212-217. doi: 10.1016/j.bbrc.2007.03.123

24. Jin Z-Q, Goetzl EJ, Karliner JS (2004) Sphingosine kinase activation mediates ischemic preconditioning in murine heart. Circulation 110:1980-1989. doi:10.1161/01.CIR.0000143632.06471 .93

25. Jin Z-Q, Karliner JS, Vessey DA (2008) Ischaemic postconditioning protects isolated mouse hearts against ischemia/reperfusion injury via sphingosine kinase isoform-1 activation. Cardiovasc Res 79:134-140. doi:10.1093/cvr/cvn065

26. Jin Z-Q, Zhou H-Z, Zhu P, Honbo N, Mochly-Rosen D, Messing RO, Goetzl EJ, Karliner JS, Gray MO (2002) Cardioprotection mediated by sphingosine-1-phosphate and ganglioside GM-1 in wild-type and PKC $\varepsilon$ knockout mouse hearts. Am J Physiol Heart Circ Physiol 282:H1970-H1977. doi:10.1152/ajpheart.01029.2001

27. Karliner JS, Honbo N, Summers K, Gray MO, Goetzl EJ (2001) The lysophospholipids sphingosine-1-phosphate and lysophosphatidic acid enhance survival during hypoxia in neonatal rat cardiac myocytes. J Mol Cell Cardiol 33:1713-1717. doi: 10.1006/jmcc.2001.1429

28. Kelly RF, Lamont KT, Somers S, Hacking D, Lacerda L, Thomas P, Opie LH, Lecour S (2010) Ethanolamine is a novel STAT-3 dependent cardioprotective agent. Basic Res Cardiol 105:763-770. doi:10.1007/s00395-010-0125-0

29. Kim RH, Takabe K, Milstien S, Spiegel S (2009) Export and functions of sphingosine-1-phosphate. Biochim Biophys Acta 179:692-696. doi:10.1016/j.bbalip.2009.02.011

30. Kleinbongard P, Heusch G, Schulz R (2010) TNF $\alpha$ in atherosclerosis, myocardial ischemia/reperfusion and heart failure. Pharmacol Therap 127:295-314. doi:10.1016/j.pharmthera.2010.05.002

31. Knapp M, Baranowski M, Czarnowski D, Lisowska A, Zabielski P, Górski J, Musiał W (2009) Plasma sphingosine-1-phosphate concentration is reduced in patients with myocardial infraction. Med Sci Monit 15:CR490-CR493

32. Kobayashi N, Nishi T, Hirata T, Kihara A, Sano T, Igarashi Y, Yamaguchi A (2006) Sphingosine-1-phosphate is released from the cytosol of rat platelets in a carrier-mediated manner. J Lipid Res 47:614-621. doi:10.1194/jlr.M500468-JLR200

33. Lacerda L, McCarthy J, Mungly SFK, Lynn EG, Sack MN, Opie LH, Lecour S (2010) TNF $\alpha$ protects cardiac mitochondria of its cell surface receptors. Basic Res Cardiol 105:751-762. doi: 10.1007/s00395-010-0113-4

34. Lecour S, Smith RM, Woodward B, Opie LH, Rochette L, Sack MN (2002) Identification of a novel role for sphingolipid signaling in $\mathrm{TNF} \alpha$ and ischemic preconditioning mediated cardioprotection. J Mol Cell Cardiol 34:509-518. doi:10.1006/jmcc.2002.1533

35. Lupiński SL, Schlicker E, Pędzińska-Betiuk A, Malinowska B (2011) Acute myocardial ischemia enhances the vanilloid TRPV1 and serotonin 5-HT(3) receptor-mediated Bezold-Jarisch reflex in rats. Pharmacol Rep 63:1450-1459

36. Matsui T, Tao J, Monte F, Lee K-H, Li L, Picard M, Force TL, Franke TF, Hajjar RJ, Rosenzweig A (2001) Akt activation preserves cardiac function and prevents injury after transient cardiac ischemia in vitro. Circulation 104:330-335. doi:10.1161/01. CIR.104.3.330

37. Means CK, Brown JH (2009) Sphingosine-1-phosphate receptor signalling in the heart. Cardiovasc Res 82:193-200. doi: 10.1093/cvr/cvp086

38. Means CK, Xiao Ch-Y, Li Z, Zhang T, Omens J, Ishii I, Chun J, Brown JH (2007) Sphingosine 1-phosphate S1P2 and S1P3 receptor-mediated Akt activation protects against in vovo myocardial ischemia-reperfusion injury. Am J Physiol Heart Circ Physiol 292:H2944-H2951. doi:10.1152/ajpheart.01331.2006

39. Mitra P, Oskeritzian CA, Payne SG, Beaven MA, Milstein S, Spiegel S (2006) Role of ABCC1 in export of sphingosine 1-phosphate from mast cells. Proc Natl Acad Sci USA 103:16394-16399. doi:10.1073/pnas.0603734103

40. Pappu R, Schwab SR, Cornelissen I, Pereira JP, Regard JB, Xu Y, Camerer E, Zheng YW, Huang Y, Cyster JG, Coughlin SR (2007) Promotion of lymphocyte egress into blood and lymph by distinct sources of sphingosine-1-phosphate. Science 316:295-298. doi: 10.1126/science. 1139221

41. Riboni L, Viani P, Bassi R, Prinetti A, Tettamanti G (1997) The role of sphingolipids in the process of signal transduction. Prog Lipid Res 36:153-195. doi:10.1016/S0163-7827(97)00008-8

42. Romiti E, Vasta V, Meacci E, Farnararo M, Linke T, Ferlinz K, Sandhoff K, Bruni P (2000) Characterization of sphingomyelinase activity released by thrombin-stimulated platelets. Mol Cell Biochem 205:75-81. doi:10.1023/A:1007041329052

43. Sato K, Malchinkhuu E, Horiuchi Y, Mogi C, Tomura H, Tosaka M, Yoshimoto Y, Kuwabara A, Okajima F (2007) Critical role of ABCA 1 transporter in sphingosine 1-phosphate release from astrocytes. J Neurochem 103:2610-2619. doi:10.1111/j.1471-4159. 2007.04958.x

44. Sattler KJE, Elbasan S, Keul P, Elter-Schulz M, Bode C, Gräler MH, Bröcker-Preuss M, Budde T, Erbel R, Heusch G, Levkau B (2010) Sphingosine 1-phosphate levels in plasma and HDL are altered in coronary artery disease. Basic Res Cardiol 105:821-832. doi:10.1007/s00395-010-0112-5

45. Takabe K, Paugh SW, Milstien S, Spiegel S (2008) "Inside-Out" signaling of sphingosine-1-phosphate: therapeutic targets. Pharmacol Rev 60:181-195. doi:10.1124/pr.107.07113

46. Tani M, Ito M, Igarashi Y (2007) Ceramide/sphingosine/sphingosine 1-phosphate metabolism on the cell surface and in the intracellular space. Cell Sign 19:229-237. doi:10.1016/j.cellsig. 2006.07.001

47. Tani M, Sano T, Ito M, Igarashi I (2005) Mechanism of sphingosine and sphingosine 1-phosphate generation in human platelets. J Lipid Res 46:2458-2467. doi:10.1194/jlr.M500268-JLR200

48. Tao R, Hoover HE, Honbo N, Kalinowski M, Alano CC, Karliner JS, Raffai R (2010) High-density lipoprotein determines adult mouse cardiomyocyte fate after hypoxia reoxygenation through lipoproteinassociated sphingosine-1-phosphate. Am J Physiol Heart Circ Physiol 298:H1022-H1028. doi:10.1152/ajpheart.00902.2009

49. Theilmeier G, Schmidt Ch, Herrmann J, Keul P, Schäfers M, Herrgott I, Mersmann J, Larmann J, Hermann S, Stypmann J, Schober O, Hildebrand R, Schulz R, Heusch G, Haude M, Wnuck Lipinski K, Herzog C, Schmitz M, Erbel R, Chun J, Levkau B (2006) High-density lipoproteins and their constituent, sphingosine-1phosphate, directly protect the heart against ischemia/reperfusion injury in vivo via the S1P3 lysophospholipid receptor. Circulation 114:1403-1409. doi:10.1161/CIRCULATIONAHA.105.607135

50. Thielmann M, Dörge H, Martin C, Belosjorow S, Schanke U, Sand A, Konietzka I, Büchert A, Krüger A, Schultz R, Heusch G (2002) Myocardial dysfunction with coronary microembolization: signal transduction though a sequence of nitric oxide, tumor necrosis factor- $\alpha$, and sphingosine. Circ Res 90:807-813. doi: 10.1161/01.RES.0000014451.75415.36 
51. Venkataraman K, Lee YM, Michaud J, Thangada S, Ai Y, Bonkovsky HL, Parikh NS, Habrukowich C, Hla T (2008) Vascular endothelium as a contributor of plasma sphingosine 1-Phosphate. Circ Res 28:669-676. doi:10.1161/CIRCRESAHA.107.165845

52. Wenkataraman K, Thangada S, Michaud J, Lin OOM, Al Y, Lee Y-M, Wu M, Parokh N, Khan F, Proia R, Hla T (2006) Extracellular export of sphingosine kinase-1a contributes to the vascular S1P gradient. Biochem J 397:461-471. doi:10.1042/BJ20060251

53. Vessey DA, Kelley M, Karliner JS (2005) A rapid radioassay for sphingosine kinase. Anal Biochem 337:136-142. doi: 10.1016/j.ab.2004.10.032

54. Vessey DA, Li L, Honbo N, Karliner JS (2009) Sphingosine 1-phosphate is an important endogenous cardioprotectant released by ischemic pre- and postconditioning. Am J Physiol Heart Circ Physiol 297:H1429-H1435. doi:10.1152/ajpheart.00358.2009

55. Vessey DA, Li L, Kelley M, Karliner JS (2008) Combined sphingosine, S1P and ischemic postconditioning rescue the heart after protracted ischemia. Biochem Biophys Res Commun 375:425-429. doi:10.1016/j.bbrc.2008.08.022

56. Vessey DA, Li L, Kelley M, Zhang J, Karliner JS (2008) Sphingosine can pre- and post-condition heart and utilizes a different mechanism from sphingosine 1-phosphate. J Biochem Mol Toxicol 22:113-118. doi:10.1002/jbt.20227

57. Yatomi Y, Ruan F, Hakomori S, Igarashi Y (1995) Sphingosine1-phosphate: a platelet-activating sphingolipid released from agonist-stimulated human platelets. Blood 86:193-202

58. Yatomi Y, Yamamura S, Ruan F, Igarashi Y (1997) Sphingosine 1-phosphate induces platelets activation through an extracellular action and shares a platelet surface receptor with lysophosphatidic acid. J Biol Chem 272:5291-5297. doi:10.1074/jbc.272.8.5291

59. Zhang DX, Fryer RM, Hsu AK, Gross GJ, Campbell WB, Li P-L (2001) Production and metabolism of ceramide in normal and ischemic-repefused myocardium of rats. Basic Res Cardiol 96:267-274. doi:10.1007/s003950170057

60. Zhang J, Honbo N, Goetzl EJ, Chatterjee K, Karliner JS, Gray MO (2007) Signals from type 1 sphingosine 1-phosphate receptors enhance adult mouse cardiac myocyte survival during hypoxia. Am J Physiol Heart Circ Physiol 293:H3150-H3158. doi:10.1152/ ajpheart.00587.2006 